\title{
A estrutura socioespacial da região metropolitana de Belém: de 1990 a 2000
}

Ana Claudia Duarte Cardoso - Prof ${ }^{a}$. Dr ${ }^{a}$. do Departamento de Arquitetura e Urbanismo da UFPA.

José Júlio Ferreira Lima - Prof. Dr. do Departamento de Arquitetura e Urbanismo da UFPA.

Lucinda Freitas de Assis Sena - arquiteta e mestre em engenharia civil pelo Programa de Pós-graduação em Engenharia Civil da UFPA.

Ricardo Bruno Nascimento dos Santos - economista e doutorando no curso de Economia Aplicada da Universidade Federal de Viçosa.

Sandra Helena Ribeiro Cruz - mestrado em Planejamento do Desenvolvimento e é doutoranda do Núcleo de Altos Estudos Amazônicos da UFPA.

\section{Resumo}

O paper apresenta um estudo sobre a estrutura social da RMB, principal formação urbana do estado do Pará no período de 1990 a 2000. Para tal, utiliza-se de análise estatística georreferenciada de dados dos censos do IBGE para retratar a estrutura sócio-espacial da Belém metropolitana, tomando-se o recorte espacial urbano do conjunto das cinco municipalidades que compõem oficialmente a Região Metropolitana de Belém (Municípios de Belém, Ananindeua, Marituba, Benevides e Santa Bárbara do Pará). São feitas comparações sobre a formação social por meio de categorias sócio-ocupacionais definidas a partir de análises fatoriais e de componentes para relacionar a divisão social e do trabalho aos impactos causados pelos projetos econômicos voltados a exploração mineral e energética no seu espaço intra-urbano.

\section{Palavras-chave}

Região Metropolitana de Belém, espaço intra-urbano, estrutura sócio-espacial.

\section{Abstract}

The paper presents a study on the social structure of the RMB, main urban formation of the Pará State from 1990 to 2000 period. Georreferenciated statistical analysis has been used with IBGE data census in order to reflect the sociospacial structure of Metropolitan Belém and taking the spacial urban clip of the five municipalities together which comprises officially the Metropolitan Region of Belém, concerning Belém, Ananindeua, Marituba, Benevides e Santa Bárbara do Pará. Comparison has been done on social formation by the means of the sociocupational categories defined hence the factorial analysis besides components in order to relate both social and labor divisions and its impacts caused by economic projects envolving both mineral and energetic exploration in its intraurban space.

\section{Keywords}

Belém Metropolitan Region, intraurban space, sociospacial structure. 


\section{INTRODUÇÃO}

O quadro de desigualdades sociais no Estado do Pará tem-se acentuado em função da instalação de projetos de exploração de recursos naturais da Amazônia. Pondo em foco a estrutura social da região metropolitana de Belém (RMB), principal formação urbana do Estado do Pará no período de 1990 a 2000, este trabalho tem como objetivo mostrar evidências capazes de relacionar o perfil da sociedade urbana de Belém aos impactos causados pelos projetos econômicos voltados para a exploração mineral e energética e relacionados à expansão da fronteira agrícola no Estado do Pará.

Evidências iniciais de modificações na estrutura social do Estado mostram que a introdução dos projetos minerais e energéticos fortaleceu a posição de entreposto de serviços e a concentração de população de baixa renda em Belém, na medida em que a cidade não recebeu investimentos que viabilizassem sua inserção na dinâmica do capital internacional instalado na região, como ocorrera em Manaus, por exemplo. A cada projeto instalado no Estado, correspondeu um aumento expressivo da informalidade no mercado de trabalho e conseqüentemente no processo de ocupação do espaço urbano, que não foi dotado de infra-estrutura compatível com o processo de ocupação em curso nas cidades próximas ao local de implantação dos projetos e na região metropolitana de Belém.

As análises aqui referidas buscam retratar a estrutura socioespacial da Belém metropolitana, com base em um recorte espacial urbano que abrange o conjunto das cinco municipalidades que compõem oficialmente a RMB. Mesmo que incompleto, por não aprofundar as análises englobando o entorno rural que cerca a área urbana, e que ilustra as diversas manifestações do rural existentes na Amazônia, o trabalho aponta indícios incompletos de uma realidade complexa, para a qual a transição rural-urbana é um elemento relevante. Ainda que essa transição não seja o foco principal deste artigo, é um dos fatores importantes para que se complete o retrato da situação socioespacial da metrópole.

\section{Formação espacial e caracterização geral da região metropolitana de Belém}

A região metropolitana de Belém (RMB), até 1995, era composta por apenas dois municípios: Belém e Ananindeua. A institucionalização inicial de 1973 pela Lei Complementar do Governo Federal foi alterada em 1995, quando a região foi ampliada e dela passaram a fazer parte, além dos municípios iniciais, o município de Benevides e o novo município de Marituba. O município de Marituba foi formado em 1991 a partir do desmembramento de parte do distrito de Benfica, pertencente anteriormente ao município de Benevides. Por último, o município de Santa Bárbara foi criado em dezembro de 1996 após desmembrar-se de Benevides, passando a constituir a RMB. A Tabela 1 apresenta os 
dados de população e o ano de instalação de cada um dos municípios, enquanto a Figura 1 apresenta uma imagem de satélite com a definição dos limites municipais.

Tabela 1: Informações gerais sobre os municípios da RMB (2000).

\begin{tabular}{|c|c|c|c|c|}
\hline Mnnicípio & Popnlaçāo & $\begin{array}{c}\text { Ano de in stalaçāo } \\
\text { do mnnicípio }\end{array}$ & Área (kmz) & $\begin{array}{c}\text { Den zidade } \\
\text { popnlacional } 2000\end{array}$ \\
\hline Ananindeua & 393.569 & 1943 & 191,4 & 2053 \\
\hline Belém & 1.280 .614 & 1616 & 1070,1 & 1196 \\
\hline Benerides & 35.546 & 1961 & 177.7 & 198,9 \\
\hline Marituba & 74.429 & 1993 & 109,1 & 691.5 \\
\hline Santa Bárbara do Pará & 11.378 & 1997 & 279.4 & 40,7 \\
\hline
\end{tabular}

Fonte: PNUD, 2001.



Figura 1: Mapa com a abrangência dos dados do Instituto Brasileiro de Geografia e Estatística (IBGE) para a região metropolitana de Belém. Fonte: Imagem de satélite Ikonos. 
O aglomerado metropolitano é constituído espacialmente por dois conjuntos fisiográficos: uma área continental e um conjunto insular com mais de 40 ilhas. Há de se destacar que a área mais densamente ocupada representa a conurbação iniciada na década de 70 e envolve, já no final da década de 80, porções urbanas que se expandem na direção dos municípios de Marituba e Benevides. O crescimento em direção a Santa Bárbara só ocorre nos anos 90 e ainda hoje é marcado pelo caráter rural da ocupação, que continua, no entanto, a depender dos municípios de Belém e Ananindeua para emprego e serviços públicos.

A seqüência de redefinições dos limites dos municípios que compõem a RMB é por si um indício do processo político e econômico que envolve a formação de novas municipalidades no Brasil e na Região Norte. Particularmente na Amazônia, a formação de novos municípios tem sido utilizada como estratégia política para reforçar a presença do poder público na região: dadas a extensão e a baixa densidade do território, a instalação de novas municipalidades permitia que lideranças políticas destituídas de responsabilidade surgissem no cenário político local. O aumento da máquina administrativa proporciona novos canais para a implantação de políticas federais voltadas para a redução das desigualdades entre populações tradicionais e os novos grupos sociais que se organizam devido aos fluxos migratórios constantes de outras regiões.

Belém, o principal município, é o único cuja taxa de crescimento da população tem sido relativamente baixa, quando comparada com as taxas de crescimento absoluto das outras cidades da região amazônica. A região metropolitana de Belém cresceu 3,69\% anualmente entre 1970 e 1991, a menor taxa entre as 15 municipalidades mais populosas da Amazônia. Essa taxa foi quase a metade da taxa de crescimento da população em Manaus no mesmo período, 6,17\%, o que eliminou a supremacia populacional e funcional de Belém em relação a Manaus (IBGE, 1992) e revelou o padrão de crescimento de cidades menores que funcionam como pólos regionais no Estado do Pará.

Do ponto de vista intra-urbano, a cidade de Belém destaca-se como a principal formação urbana da região metropolitana de Belém (Figura 2). Sua estrutura espacial tem relações claras com sua estratificação social. A ocupação do território é marcada desde o seu início por limitações impostas pela formação geográfica e pelas condições físicas do sítio. De acordo com a concepção inicial de expansão da cidade, as áreas altas e firmes destacaram-se como local de agregação de investimentos em infra-estrutura e foram adotadas como local de moradia da elite local, caracterizando-se pelo alto padrão construtivo das edificações. Observe-se que essas áreas adensaram-se durante o ciclo da borracha, época em que a referência de urbanidade na cidade era Paris, e receberam ruas e passeios públicos amplos, praças de rica composição e concentração de palacetes ecléticos (SARGES, 2000). Por outro lado, a população pobre subdividia-se em dois grupos: um nascido em Belém, que ocupava áreas intermediárias entre as terras firmes e 
as alagadas; outro formado pelos pobres migrantes, a princípio oriundos do interior do Estado, que se estabeleciam nas "baixadas" da cidade, áreas alagáveis, mas fortemente ligadas à dinâmica ribeirinha, graças à proximidade de portos que favoreciam a mobilidade entre a cidade e suas ilhas e o interior. Além disso, as baixadas tornaram-se historicamente o espaço disponível para a população de baixa renda, conforme será abordado diversas vezes ao longo do texto.

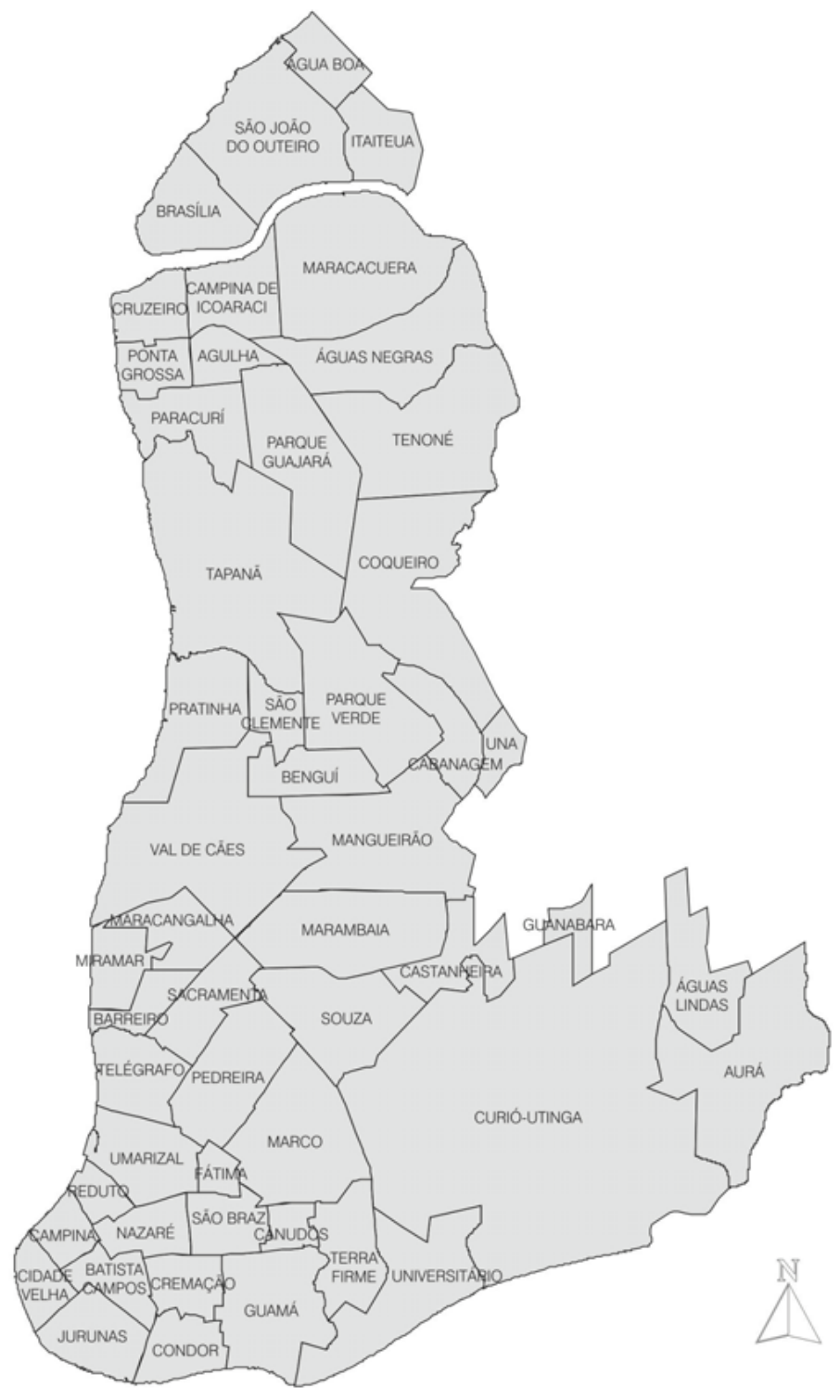

Figura 2: Mapa com os bairros da porção continental e da ilha de Caratateua.

Fonte: Elaborado pelo Departamento de Arquitetura e Urbanismo (DAU) da Universidade Federal do Pará (UFPA), com base na lei de delimitação dos bairros de Belém, Lei n. ${ }^{0}$ 7.603, 13 de janeiro de 1993. 




Figura 3: Plano de alinhamento para a primeira légua patrimonial do município de Belém, desenhado por José Sydrim em 1901.

Fonte: IHG, Rio de Janeiro, reproduzido em Alunorte (1995).

A implantação, pela administração municipal, de um plano de alinhamento (Figura 3) em toda a primeira légua patrimonial a partir da primeira década do século XX, constituiu-se, a longo prazo e após uma série de investimentos em macrodrenagem nas décadas de 70, 80 e 90, em um instrumento para superação das dificuldades iniciais de acessibilidade. Alguns bairros e eixos de expansão abrigam, desde a

\footnotetext{
${ }^{1}$ Em 1. ${ }^{\circ}$ de setembro de 1627, onze anos após a fundação da cidade de Belém, o Governo da Província do Maranhão e Grão-Pará, por meio da Carta de Doação e Sesmaria, doa ao Conselho da Câmara de Belém uma légua patrimonial, para que pudesse explorá-la economicamente, exercendo assim o jus domine; posteriormente, em 29 de março de 1628, o Conselho da Câmara toma posse do patrimônio, por meio do Auto de Posse da Légua Patrimonial da Câmara de Belém. Essa légua foi demarcada em 20 de agosto de 1703. Esse território corresponde hoje à porção dotada de melhor infra-estrutura e mais valorizada da RMB.
} 
segunda metade do século XIX, a elite dirigente local e intelectual, os prósperos comerciantes portugueses, os proprietários fundiários, fazendeiros, empresários da navegação, seringalistas, etc. e, atualmente, empresários e profissionais liberais. Trata-se dos bairros da Cidade Velha e da Campina, cujas áreas correspondem às cotas mais altas do núcleo original da cidade, estendendo-se a partir delas em direção às margens dos rios internos, da baía e do rio Guamá, aproximando-se das baixadas.

Até os anos 60 do século XX, os gestores municipais admitiam sua impotência diante do montante de investimentos necessários para promover a integração entre as terras firmes e as baixadas da cidade, e muitos slogans de campanha prometiam a construção de estivas, visto que o custo de ações de macrodrenagem era muito elevado em relação às receitas municipais (BELÉM, 1987). Durante a ditadura militar, ocorreu uma mudança significativa nessa situação, com a chegada de investimento federal à cidade (obras de saneamento e financiamento de habitação), o que um marco importante, apesar da dissociação entre políticas. Grandes investimentos foram feitos em obras de saneamento que permitiriam a transposição de obstáculos entre áreas já consolidadas, criando-se ligações previstas desde o plano de alinhamento proposto para Belém no final do século XIX, enquanto os investimentos em habitação eram pensados para fora da primeira légua e em quantidades suficientes para literalmente desenharem a expansão da cidade, ainda que isso não tenha sido concebido dessa forma.

Com a construção dos conjuntos habitacionais em áreas rurais localizadas no limite da primeira légua patrimonial, muito afastadas do centro urbano, constituíram-se interstícios que se tornaram objeto de invasões. Na passagem dos anos 80 para os anos 90, políticos incentivavam explicitamente as invasões e apresentavam a regularização das invasões como promessa de campanha nos veículos de comunicação de massa. Teve então início o que diversos autores chamaram "indústria das invasões", fenômeno que distorceu o processo de enfrentamento entre os proprietários de terra e os segmentos "operários" da população (BORGES, 1992; CARDOSO, 2002; IPEA, 2002; TRINDADE JÚNIOR, 1998).

A área de expansão de Belém, estruturada ao longo da rodovia Augusto Montenegro, foi ocupada por vários conjuntos habitacionais de grande porte, a partir da década de 70 (Cidades Novas, via rodovia do Coqueiro, Maguari, Satélite, Pedro Teixeira, etc.), e foi rapidamente objeto de investimentos em outro segmento do mercado de habitação, os condomínios fechados, surgidos durante os anos 90, como alternativa de moradia horizontal para as classes altas. Essa alternativa já tinha sido testada em Ananindeua, mas de forma discreta; na década de 90, o marketing realizado pela Construtora Vila Del Rey deu maior visibilidade ao processo e inaugurou a disputa dos lotes lindeiros à rodovia Augusto Montenegro por segmentos de alta renda e por populares, empurrando para trás os mais pobres, que se estabeleceram 
novamente em invasões. Nesse período o processo de invasão alcançou conjuntos habitacionais não acabados por problemas de financiamento, como o conjunto residencial Jardim Sevilha, retardando um pouco a definição do status que prevaleceria na primeira década do século XXI (quando houve um significativo aumento dos condomínios fechados ao longo da rodovia) (Figura 4).

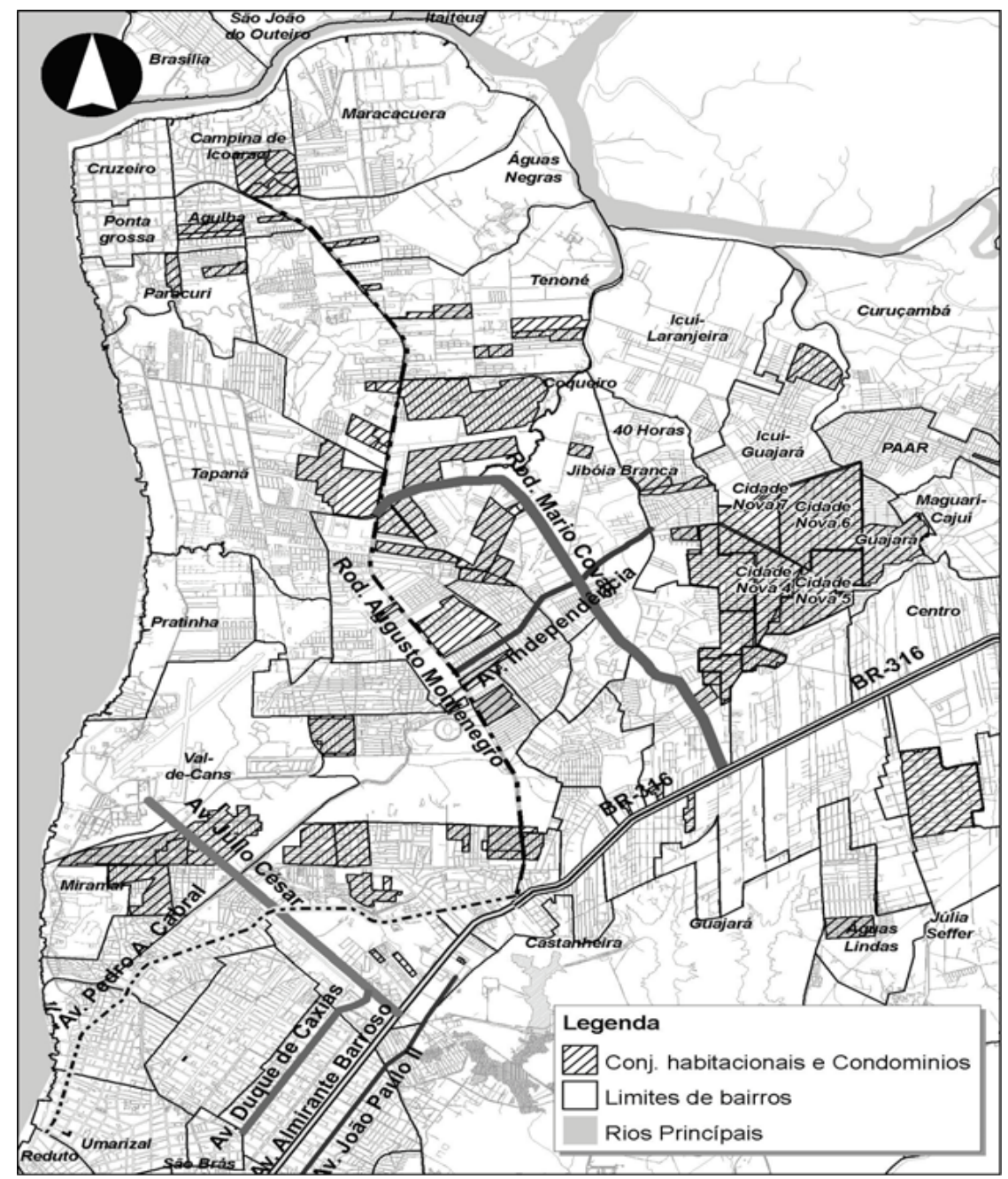

Figura 4: Mapas com indicação do crescimento da periferia por meio de condomínios e de áreas de assentamento irregulares.

A necessidade de aperfeiçoamento da gestão da Secretaria de Finanças viabilizou o acesso à linha específica de financiamento do Banco Nacional de Desenvolvimento Econômico e Social (BNDES). Foi feito um cadastro técnico em 1977, concluído em 1999, que permitiu atualizar a cartografia disponível (o último levantamento ocorrera em 1977). Nessa época também foi realizado, pelo Governo do Estado, um levantamento aerofotogramétrico da RMB, o que permitiu uma avaliação mais precisa das condições de ocupação do território nos demais municípios constituintes da RMB. 
Em 1993 houve a redefinição dos limites entre Belém e Ananindeua e, em 1995, conforme citado anteriormente, houve a ampliação da região metropolitana de Belém, com a incorporação dos municípios de Marituba, Benevides e Santa Bárbara. As áreas de mananciais foram negociadas de modo que ficassem incorporadas ao território de Belém, enquanto a Cidade Nova foi cedida ao município de Ananindeua. Não houve avanço na legislação e na gestão municipal nos demais municípios da RMB, nem integração oficial de políticas intermunicipais. A região dos mananciais (lagos Bolonha e Água Preta) criou um obstáculo à expansão da RMB ao longo da margem direita da BR-316, enquanto as conexões viárias criadas entre a área de expansão de Belém e a Cidade Nova favoreceram a intensificação da ocupação na margem esquerda da rodovia BR-316 (Figura 5).

A atuação do governo do Estado na RMB ao longo de três gestões consecutivas foi marcada pelo apoio à restauração de monumentos históricos, como parte de uma política de apoio ao turismo. Na passagem da década de 90 para 2000, foram inaugurados, pelo Governo do Estado, a Estação das Docas e o Complexo Feliz Lusitânia (a Igreja de Santo Alexandre esteve em obras de restauração durante 50 anos) e, pela Prefeitura Municipal de Belém, o complexo Ver-o-Peso. Teve início nesse período um movimento pela apropriação da orla da cidade pela população, que visava fortalecer atividades de contemplação em oposição à desordem causada pela superposição de atividades produtivas, como ocorreu na reforma dos pavilhões do porto, transformados na Estação das Docas.

As transformações citadas, no território e em sua gestão, foram muito bem interpretadas e apropriadas pelo setor privado. A obsolescência da infra-estrutura do bairro comercial, o crescimento urbano e as melhorias de infra-estrutura realizadas na primeira légua patrimonial de Belém ensejaram movimentos sucessivos de dispersão pelas principais empresas do setor. Merece destaque a estratégia dos supermercados de se estabelecerem em pontos estratégicos da cidade, inicialmente com cadeias nacionais, que depois foram adquiridas por cadeias locais, que assumiram o monopólio do setor. A chegada dos hipermercados aos centros dos bairros foi um passo decisivo para a consolidação desses equipamentos, que passaram a oferecer um "mix" de lojas, serviços e produtos (serviços bancários, restaurantes, centro lotérico, banca de revista) capazes de rivalizar com a antiga feira livre. Esse processo atinge seu ápice com a inauguração simultânea de dois shopping centers, um deles na área de entorno do centro histórico (da cadeia Iguatemi) e outro no Entroncamento (de capital local).

A difusão dos hipermercados foi reforçada pela distribuição das lojas de departamento pelos centros dos bairros, algumas vezes associadas aos supermercados (em uma primeira fase, o grupo Y. Yamada construiu lojas na Pedreira, no Marco, em Batista Campos e em São Braz). Tal processo consolidou a primeira légua patrimonial de 
Belém como centro da RMB, região onde predomina a diversidade de usos, principalmente ao longo dos principais corredores de tráfego (aqui destacados como centros de bairro) constituídos após intervenções nas condições de infra-estrutura. Nesse movimento de dispersão das atividades de comércio e serviços, observa-se a especialização e a diferenciação do status de algumas áreas. Prevaleceu, entretanto, a tendência à privatização das atividades, com oferta de estacionamento, condicionamento de ar e vigilância privada. Em contrapartida, observouse a tomada de ruas e calçadas pelo comércio informal, principalmente no antigo bairro do Comércio e na avenida Presidente Vargas, fenômeno que não modificou o perfil socioeconômico e a tipologia ocupacional dos residentes daquelas áreas, segundo o censo de 2000 (IBGE, 2002), conforme definidos no item 2 .

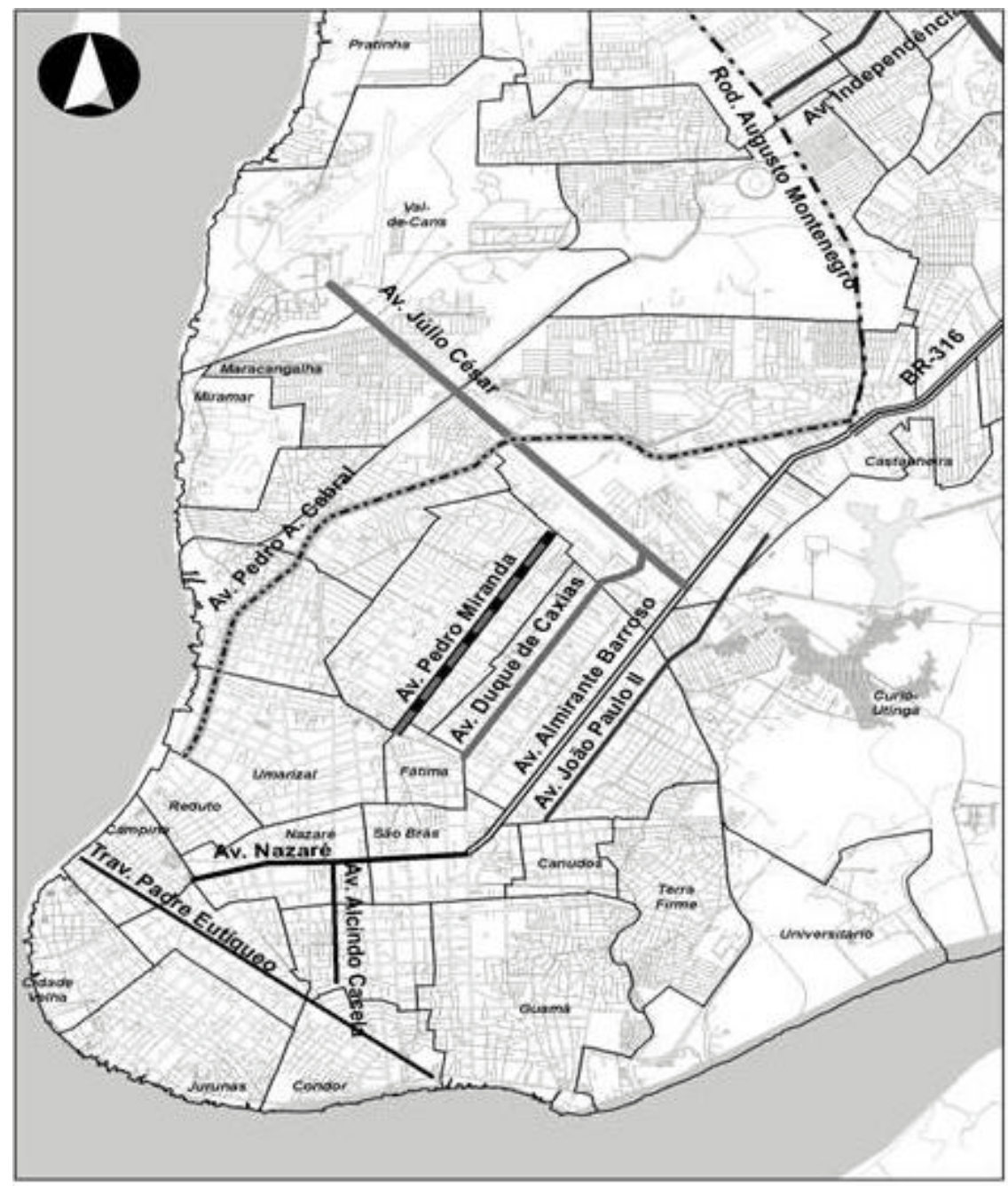

Figura 5: Mapa com a indicação de eixos comerciais e de concentração de serviços na primeira légua patrimonial.

O tratamento de conjuntos arquitetônicos de interesse turístico e a manutenção dos vínculos da cidade com a região ribeirinha, por meio das 
feiras e da mobilidade da população graças ao transporte fluvial, são fatores que contribuem para a manutenção da vitalidade do bairro do Comércio; por outro lado, observa-se que o comércio informal tende a ocupar todos os espaços caracterizados pela centralidade diferenciada, alcançando os centros dos bairros e as avenidas de grande fluxo de transporte coletivo, como as avenidas Presidente Vargas, Magalhães Barata e Pedro Miranda.

Fora de Belém, destacam-se as obras de pavimentação na Cidade Nova, que reforçaram o processo de formação da centralidade em Ananindeua. As transformações tiveram início com a instalação de um hipermercado, seguida por filiais de escolas privadas de ensino fundamental e médio, estabelecimentos de ensino superior, escola de idiomas e outros hipermercados, o que modificou significativamente as condições de vida na área. O estímulo à transformação foi reforçado com a construção da avenida Independência e a requalificação da antiga rodovia do Coqueiro, atual avenida Mário Covas.

Na década de 90, houve uma tentativa frustrada de implantação de um condomínio fechado no bairro do Tenoné, que atraía pela possibilidade de construção de uma marina na margem do rio Maguari, que separa os municípios de Belém e Ananindeua. Esse objetivo foi concretizado em solo de Benevides, que, apesar de mais afastado de Belém, passou a receber em seus bairros centrais a classe média que abandonava Belém e, em sua zona rural, membros da elite local, em casas de final de semana (primeiro escalão do executivo estadual, deputados, empresários, etc.). Como os dados manipulados pela pesquisa referem-se apenas às áreas consideradas urbanas pelo censo do IBGE de 2000, esses processos ainda não podem ser detectados pela observação da distribuição do perfil socioeconômico e da tipologia ocupacional dos ocupantes por setor censitário. Nos demais municípios, a ocupação da periferia urbana e da área rural ocorre por invasões e loteamentos estabelecidos de modo desarticulado, como na área de expansão de Belém. Tal processo novamente dificulta a consolidação e a implantação de usos não residenciais.

\section{A economia da RMB a partir da década de 80}

A evolução do Produto Interno Bruto (PIB) da RMB, no período de 1980 a 1990, refletiu o quadro de dificuldades da economia brasileira. Mas, enquanto o PIB nacional cresceu apenas cerca de 1,8\% (BELÉM, 1992), o PIB da RMB teve incremento anual em torno de $3 \%$, em decorrência de efeitos indiretos do crescimento econômico de outras áreas do Estado do Pará. Nesse período, grandes projetos minerais e metalúrgicos foram implantados e intensificou-se a exploração madeireira. Como a RMB representava o principal ponto de escoamento e o centro de negócios, esses projetos levaram a uma concentração de serviços especializados, porém abaixo das necessidades de geração de emprego e de renda que permitisse a melhoria do padrão de vida de grandes contingentes populacionais urbanos. 


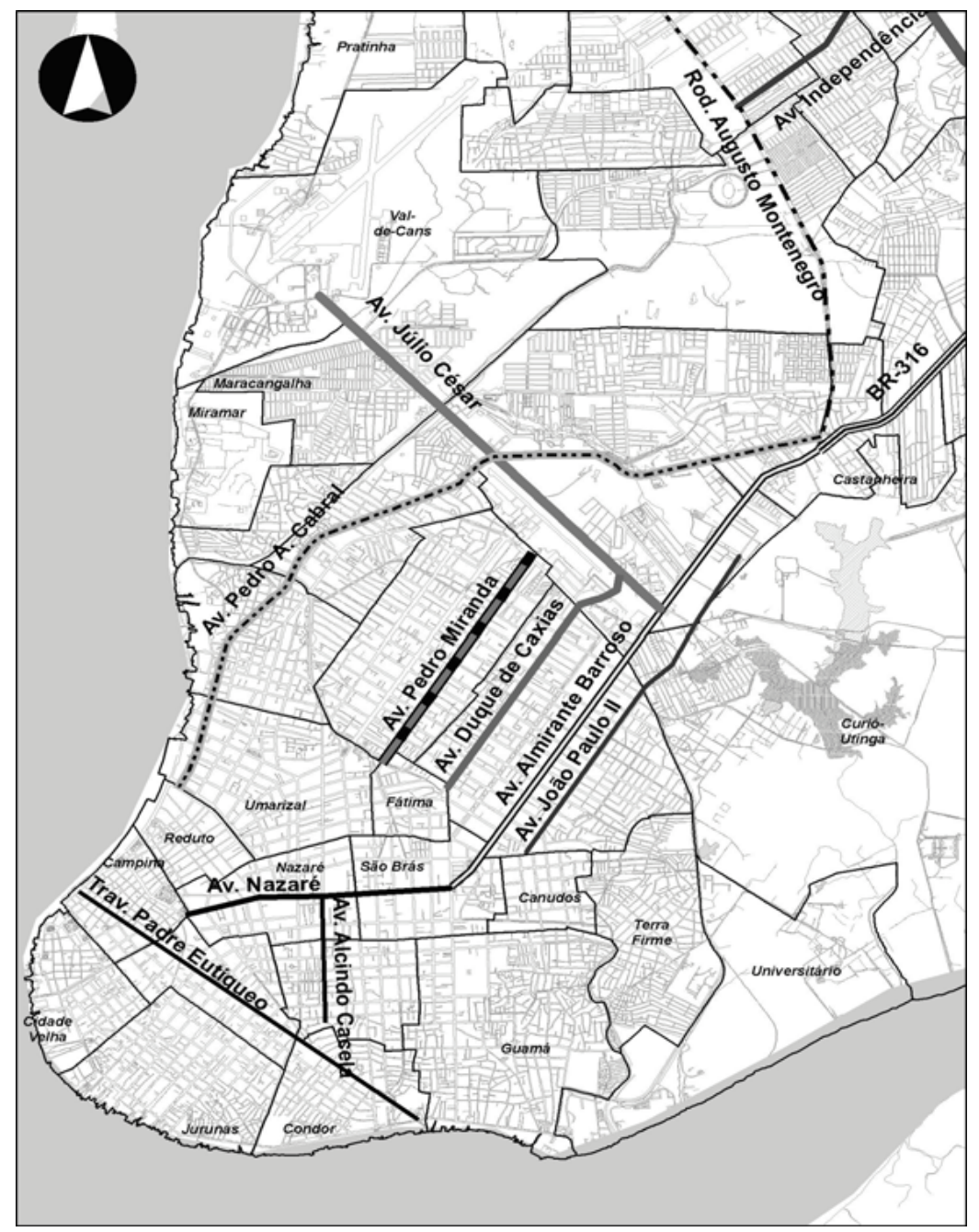

Figura 6: Mapa mostrando novos eixos metropolitanos.

Dos setores econômicos, o mais importante na RMB é o terciário, ocupando cerca de $80 \%$ da população economicamente ativa. Seu melhor desempenho deu-se nas décadas de 80 e 90. Enquanto o setor primário teve um crescimento médio de 5,8 \%, com uma participação no PIB regional de 0,3\%, em 1980, e de 0,4\%, em 1990, e o secundário, de 1,02\%, o crescimento médio anual do setor terciário foi de 4,3\% (excluindo autônomos, setor público e outros serviços).

Os anos de 80 e 90 são ainda marcados por baixos índices de ocupação, produção e faturamento. Houve uma significativa queda no mercado interno da RMB. O setor primário teve um crescimento médio anual de 5,81\%, pouco significativo, dada sua minúscula participação no PIB total da RMB (0,3\% em 1980 e 0,4\% em 1990). Já no setor secundário, o crescimento anual do estoque de empregos formais na indústria de transformação foi de apenas 2,8\% contra 4,3\% ao ano do total de empregos na RMB. Houve um decréscimo no número de empregos nos setores de vestiário e calçados $(6,1 \%)$, química $(-3,7 \%)$, 
mecânica $(-3,6 \%)$ e de comunicações $(-2,1 \%)$. O processo só não foi mais grave porque houve uma expansão de demanda no interior do Estado, devido ao crescimento demográfico e econômico, motivado pelo avanço da fronteira agrícola. Os ramos que tiveram crescimento foram o de material de transporte (6,6\%), pela instalação de estaleiros apoiados por investimentos fiscais, o de papel e papelão $(5,2 \%)$, de materiais plásticos (4,3\%) e da madeira (3,7\%).

Ocorreu ainda uma grande retração na indústria da construção civil na década de 80, causada principalmente pela perda do poder aquisitivo da população, o que trouxe perda da capacidade de poupar, aumento da inadimplência e crise no Sistema Financeiro de Habitação (SFH), além de um expressivo aumento no preço de terrenos urbanos, pela especulação imobiliária, com graves problemas para a arrecadação tributária local. O setor terciário na RMB apresentou melhores resultados, confirmando a tendência verificada na década anterior. No período de 1980 a 1990, os resultados da Relação Anual de Informações Sociais (RAIS) mostram um aumento médio de 5,2\% proporcionado principalmente pelos serviços (3,2\% ao ano) e pela administração pública (9,9\% ao ano).

\subsection{A dinâmica das atividades econômicas e do mercado de trabalho}

Quanto ao mercado de trabalho, a população ocupada da RMB possui características bem específicas. A RMB apresenta uma taxa de atividade baixa, se comparada à da região Sul, que em 2003 apresentou o maior índice das Grandes Regiões, com 66,2\%, e à da região Nordeste, com 59,8\% (apresentando aqui o menor índice), e à taxa nacional de 55,4\% em 2003 (ver Tabela 2).

As atividades econômicas que tiveram maior participação no emprego formal da região metropolitana de Belém, no ano de 2002, foram comércio e serviços (63,72\%), indústria e construção (18,88\%), administração pública $(7,10 \%)$ e agrícola (1,93\%).

Tabela 2: Taxa de atividade da RMB em 2004.

\begin{tabular}{cc}
\hline PLA & 1039895 \\
\hline PEA & 568521 \\
\hline PEA/PLA & $54,67 \%$ \\
\hline
\end{tabular}

FONTE: IBGE.

As atividades econômicas que tiveram maior participação no emprego formal da região metropolitana de Belém, no ano de 2002, foram comércio e serviços (63,72\%), indústria e construção (18,88\%), administração pública $(7,10 \%)$ e agrícola (1,93\%).

Ao longo do período de 2002 a 2004, verifica-se um crescimento de 11,25\% na população ocupada, sem, contudo, haver mudanças significativas na participação das atividades em relação ao total da população ocupada. Essa evolução pode ser observada na Tabela 3. 
Tabela 3: População ocupada no território, segundo setores da economia.

\begin{tabular}{|c|c|c|c|c|c|c|}
\hline \multirow{2}{*}{ Setores da economia } & \multicolumn{2}{|c|}{2002} & \multicolumn{2}{|c|}{2003} & \multicolumn{2}{|c|}{2004} \\
\hline & H. ${ }^{\circ}$ & $\%$ & N. ${ }^{\circ}$ & $\%$ & N. ${ }^{\circ}$ & $\%$ \\
\hline Agricultura & 14.715 & 1.93 & 10.889 & 1,35 & 16.599 & 1,95 \\
\hline Indústria & 81.803 & 10.71 & 94.708 & 11.7 & 84.706 & 9.97 \\
\hline Construçāo & 62.366 & 8,17 & 69.629 & 8,6 & 76.697 & 9.03 \\
\hline Comércio e reparação & 202.216 & 26,48 & 215.980 & 26,69 & 219.045 & 25,78 \\
\hline $\begin{array}{l}\text { Alojamento e alimentaçāo } \\
\text { Transporte, armazenagem }\end{array}$ & 45.259 & 5.93 & 43.724 & 5.4 & 40.631 & 4.78 \\
\hline e comunicaçāo & 40.360 & 5,28 & 40.919 & 5,06 & 42.387 & 4,99 \\
\hline $\begin{array}{l}\text { Administraçāo publica } \\
\text { Educaçāo, saúde e serviços }\end{array}$ & 54.258 & 7.1 & 53.128 & 6.56 & 59.654 & 7,02 \\
\hline socizis & 71.978 & 9.42 & 79.034 & 9.77 & 81.592 & 9,6 \\
\hline $\begin{array}{l}\text { Serviços domésticos } \\
\text { Outros serviços coletivos, }\end{array}$ & 84.168 & 11,02 & 87.611 & 10.83 & 93.567 & 11,01 \\
\hline sociais e pessoais & 42.719 & 5.59 & 43.559 & 5,38 & 49.883 & 5.87 \\
\hline $\begin{array}{l}\text { Outras atividades } \\
\text { Atividades mal definidas ou }\end{array}$ & 55.998 & 7.33 & 61.214 & 7.56 & 68.020 & 8,01 \\
\hline nāo declaradas & 7.915 & 1.04 & 8.910 & 1,1 & 16.915 & 1.99 \\
\hline Total & 763.755 & 100 & 809.305 & 100 & 849.696 & 100 \\
\hline
\end{tabular}

FONTE: PNAD-IBGE.

Com relação ao PIB a preços correntes, fica evidente a importância que o município de Belém possui na economia do Estado, pois, na participação relativa, esse PIB representa mais de 1/4 de participação. No entanto, no período de 1999 a 2003, a participação relativa do PIB caiu. Outra importante observação diz respeito ao crescimento do PIB per capita do município, o que demonstra o aumento da produção. É evidente também o crescimento desse PIB - em 1999 era de 4,65 bilhões e em 2003 passou para 7,29 bilhões -, ou seja, houve um incremento no PIB a preços correntes de 56,58\% de 1999 a 2003. A média de crescimento anual do PIB de 1999 a 2003 é de 11,94\% (ver Tabela 4).

Tabela 4: Evolução do PIB a preços correntes de 1999 a 2003.

\begin{tabular}{ccrr}
\hline Ano & Valor R\$ (mil) & PR & per capita \\
\hline 1999 & $4.653 .598,16$ & 27,91 & $3.652,11$ \\
2000 & $5.545 .922,44$ & 29,32 & $4.278,20$ \\
2001 & $5.977 .316,18$ & 27,48 & $4.533,20$ \\
2002 & $6.552 .484,60$ & 25,67 & $4.886,10$ \\
2003 & $7.286 .518,18$ & 24,94 & $5.355,32$ \\
\hline
\end{tabular}

FONTE: IBGE.

Da análise do PIB per capita, deduz-se que o município de Belém apresenta declínio em sua participação em relação aos demais municípios do Estado (ver Tabela 5), em que há uma oscilação, com tendência de queda do PIB per capita.

156 
Tabela 5: PIB per capita a preços de mercado de Belém (de 1999 a 2002).

\begin{tabular}{ccc}
\hline ANO & PIB & ranking no Estado \\
\hline 1999 & $3.652,11$ & $24 .^{\circ}$ \\
2000 & $4.278,20$ & $19 .^{\circ}$ \\
2001 & $4.533,20$ & $24 .^{\circ}$ \\
2002 & $4.886,10$ & $29 .^{\circ}$ \\
\hline
\end{tabular}

FONTE: SEPOF, Governo do Estado.

Na série analisada de 1999 a 2003, observa-se que, para o PIB a preços correntes, o setor de serviços é o que tem a maior participação dos três principais setores econômicos. A participação desse setor é superior a 60\%, seguindo-se a indústria, com participação de aproximadamente 36,38\%, e a participação inexpressiva do setor agropecuário na economia do município de Belém (ver Tabela 6:).

Tabela 6: Valor adicionado a preços correntes por setores da economia (de 1999 a 2010*).

\begin{tabular}{|c|c|c|c|c|c|c|c|}
\hline Ano & Valor R\$ (mil) & Agr opecnária & $\mathbf{x}$ & In dí xtria & $x$ & Serviçoz & $\mathbf{x}$ \\
\hline 1999 & $4.255 .911,00$ & $11.342,00$ & 0,27 & $1.453 .798,00$ & 34,16 & $2.790 .771,00$ & 55 \\
\hline 000 & $4.870 .815,00$ & $12.096,00$ & .25 & $1.656 .931,00$ & 4,02 & $3.201 .788,00$ & o. \\
\hline 101 & 06.4 & & 27 & 1.9 & 97 & 00 & 1,7 \\
\hline 002 & 4. & & 3 & 2.0 & 54 & 00 & 8,1 \\
\hline 003 & 0 & & 24 & 2.3 & 11 & 3.7 & 0,6 \\
\hline 004 & & 0 & 24 & 2.5 & 99,11 & 3.8 & 0,8 \\
\hline 2005 & 97.5 & . & 24 & 2.658 & 39,11 & 4.122 & 0,8 \\
\hline 2006 & 6 & 10 & 24 & 2.79 & 39,11 & 4.340 & 0,65 \\
\hline 2007 & & & 24 & 2.94 & 39,11 & 4.5 & 0.8 \\
\hline 2008 & & & 4 & & 11 & & 0.8 \\
\hline 2009 & & & & & 11 & & 0. \\
\hline 2010 & $8.800 .255,36$ & $21.052,82$ & 0,24 & $3.442 .185,00$ & 39,11 & $5.337 .018,00$ & 60. \\
\hline
\end{tabular}

FONTE: IBGE.

*Valores projetados. Taxa de crescimento utilizada: 5,3\% (Governo do Estado).

3 Organização socioespacial do território da RMB: 1991/2000

A avaliação da evolução da estrutura socioespacial da região metropolitana de Belém no decorrer da década de 90 e a constatação da segregação socioespacial que segmenta o território da metrópole foram apoiadas pela metodologia desenvolvida no âmbito da rede de pesquisa "Observatório das Metrópoles", projeto do Instituto do Milênio, do Conselho Nacional de Desenvolvimento Científico e Tecnológico (CNPq), que utiliza principalmente os dados do Censo do IBGE. A análise espacial de grupos sociais no âmbito da RMB concentrou-se na construção da hierarquia social nos espaços observados, com base na noção de centralidade do trabalho na estruturação e no funcionamento da sociedade. Utilizou-se, como variável principal para a análise do espaço social, a "ocupação", como definida pelo IBGE. Construiu-se um sistema de hierarquização social das ocupações para servir de proxy da estrutura social, sintetizada em 25 categorias socioocupacionais. A metodologia utilizada prevê um primeiro recorte na construção de 
categorias socioocupacionais, baseado na divisão clássica de classes: detentores de capital versus despossuídos de capital. A partir daí, são feitos sucessivos cortes entre grande capital e pequeno capital, trabalho manual e trabalho não-manual, trabalho formal e trabalho informal, e entre setores econômicos (secundário vs terciário, moderno vs tradicional) ${ }^{2}$. Considera-se que à hierarquização social corresponde uma hierarquização no espaço. Para identificar diferenças nos ganhos e perdas nas disputas por lugares no espaço social da metrópole, buscouse aquilo que Bourdieu (1997, p. 163) chama "ganhos de ocupação" - a distância entre a manutenção da distância ou a intrusão desejável. Constata-se a materialização da hierarquia social em graus diferenciados, de acordo com a localização das diversas categorias socioocupacionais, compostas por densidades de ocorrência diferentes em cada lugar da metrópole, bem como de sua composição pelas diversas categorias indicadas na sistematização feita pelo Censo. Depreende-se daí um quadro de segregação na RMB.

A metodologia empregada leva em conta dois aspectos que se integram: de um lado, a definição de um artifício para dividir em setores o espaço, por causa das evidências de segregação social; de outro, a identificação de homogeneidade e de heterogeneidade entre residentes em cada um dos setores urbanos identificados. Para cada cidade, são definidas áreas de expansão domiciliar (AED) dos dados do Formulário 2 do Censo do IBGE. O que define a AED é a super-representação de uma categoria ocupacional em uma dada área, em relação a sua média na região metropolitana considerada. Por exemplo, uma área classificada como superior não é território exclusivo das elites, que compartilham esse espaço com setores médios e, em alguns casos, com trabalhadores do setor popular em "ilhas" de espaços intercalados, conforme percebido na RMB. O recorte territorial das AED foi feito pelo IBGE por meio de métodos e de um sistema de formação de áreas de ponderação "que conjugam critérios, tais como tamanho, contigüidade (no sentido de constituídas por conjuntos de setores limítrofes com sentido geográfico) e homogeneidade em relação a um conjunto de características populacionais e infra-estrutura conhecida" (IBGE, 2002). Para a definição de áreas, foi necessário garantir a homogeneidade interna no que se refere à realidade social e à continuidade espacial, e cada unidade deveria conter um número estatisticamente consistente de pessoas ocupadas.

O estudo baseia-se nos microdados dos censos demográficos do IBGE constantes do "Questionário 2" do Censo (IBGE, 1992, 2002). A partir de uma amostragem de 10\% constante na base censitária, a unidade espacial deveria conter no mínimo seis mil pessoas ocupadas. Estabelecidas as áreas com os dados populacionais de 1991, foram necessários ajustes para que fossem utilizados os dados de $2000 \mathrm{em}$ uma nova espacialização de dados. Algumas áreas de 2000 não constavam




no mapa de 1991. É o caso dos municípios de Marituba, Benevides e Santa Bárbara do Pará. Outra redefinição deveu-se à mudança dos limites entre os dois únicos municípios que compunham a RMB em 1991: Belém e Ananindeua. Daí as diferenças entre os mapas de 1991 e 2000.

Para a delimitação das AED no caso da RMB, foi feito um esforço conjunto no sentido de aproximá-las o mais próximo possível dos limites de bairros já consagrados localmente, considerados capazes de remeter à identidade de espaços nos municípios de Belém (Lei Municipal n. ${ }^{\circ}$ 7.806 de 30 de julho de 1996) e Ananindeua (mesmo que não possua uma delimitação oficial como Belém). Desse modo, os 941 setores censitários de 1991 foram agregados em 53 áreas, e os 1621 setores de 2000 foram agregadas em 56 áreas. Para o município de Belém, foram definidas 38 AED com as mesmas denominações dos bairros do município; para Ananindeua, 15 AED, e uma AED para cada um dos outros municípios metropolitanos restantes: Marituba, Benevides e Santa Bárbara do Pará. A Figura 7 mostra o alcance da espacialização de todos os dados do IBGE para a RMB.

Quanto ao segundo aspecto da metodologia citado acima, para identificar a segregação socioespacial, utiliza-se o teste estatístico da análise fatorial de correspondência, que permite obter índices de variância das categorias socioprofissionais indicadas pelo IBGE no preenchimento do Formulário 2 do Censo. O passo seguinte é a elaboração de um quadro da regularidade da representação das categorias no espaço da RMB. Chega-se a uma tipologia socioespacial, que expressa a "densidade" de representação das diversas categorias e sua combinação no espaço metropolitano. Emprega-se uma nomenclatura capaz de indicar ao mesmo tempo a relação de divisão social e a proximidade de cada categoria na hierarquia socioespacial A metodologia aqui mencionada foi desenvolvida por Chenu e Tabard (1993), depois aplicada por Préteceille (1995) a Paris, por Ribeiro (2000) ao Rio de Janeiro e por Mendonça (2002) a Belo Horizonte. Foi ainda aplicada a mais dez metrópoles brasileiras no âmbito da projeto Observatório das Metrópoles, coordenada nacionalmente pelo Instituto de Pós-Graduação em Planejamento Urbano e Regional (IPPUR), da Universidade Federal do Rio de Janeiro (UFRJ).

A tipologia usada para caracterizar os espaços geográficos da RMB em função da estrutura social encontrada em 2000 resultou da correlação entre as 25 categorias e as AED que englobam os territórios urbanos dos cinco municípios que compõem a referida região. Com base nessa correlação, foi efetuada uma análise da ocorrência das condições de ocupação, escolaridade, renda, posição na ocupação e ramo de produção, definidas e pesquisadas pelo IBGE, agrupando-se em 25 categorias, e presentes nos diferentes tipos de cada AED da RMB (ver Tabela 19 no Anexo). As categorias identificadas pelo IBGE foram analisadas estatisticamente nos espaços definidos na RMB e organizadas pela ocorrência (números absolutos e densidades) em tipos. Cada tipo 
é composto por representantes de todas as categorias em diferentes quantidades. Foram considerados os seguintes tipos:

a) grupo superior: concentração de categorias socioocupacionais dirigentes e de profissionais de ensino superior;

b) grupo médio: presença da pequena burguesia e de setores médios acima da média metropolitana ou perto dela, além de categorias operárias e populares;

c) grupo popular: forte presença de operários diversos, trabalhadores não especializados e categorias do subproletariado.

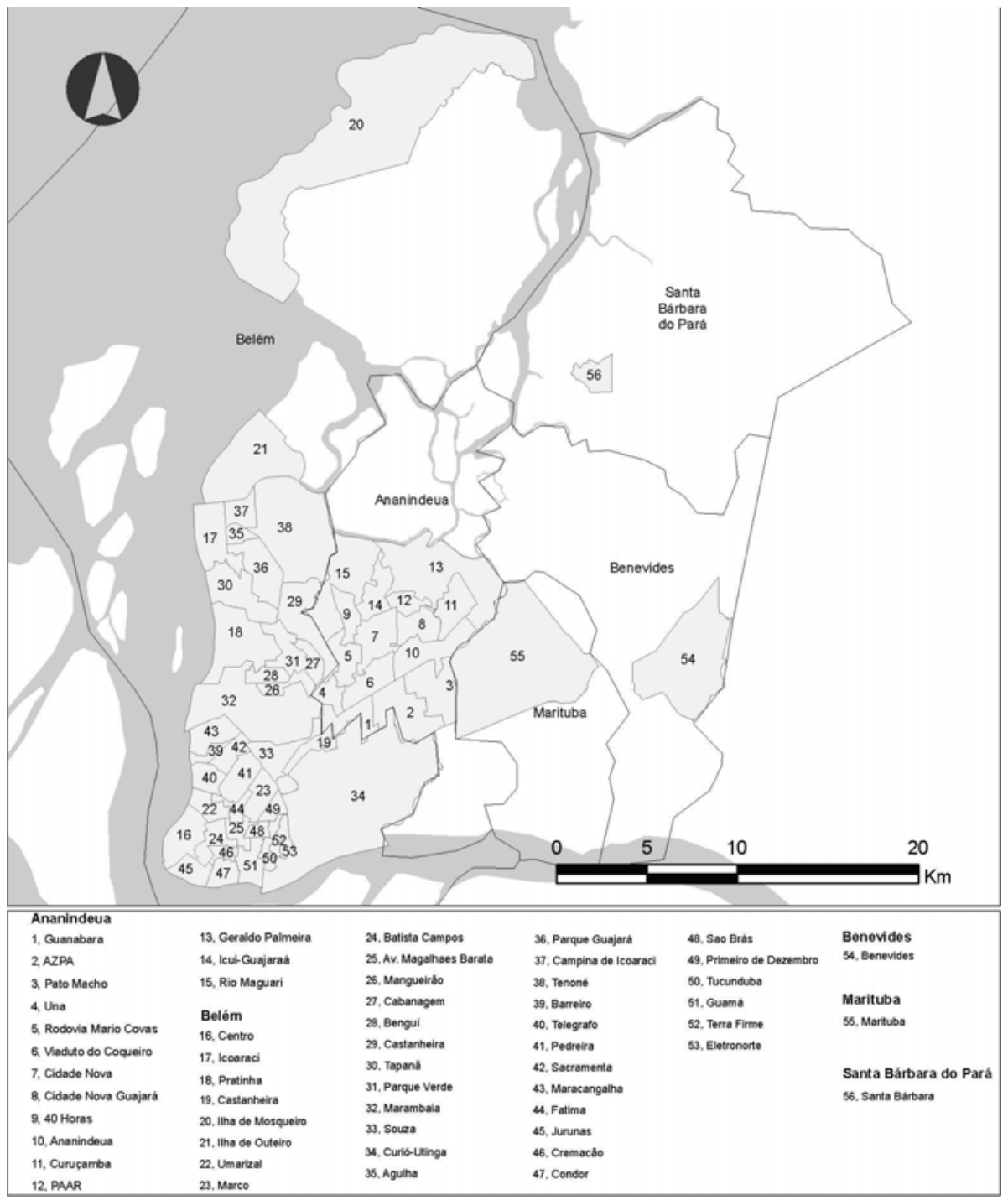

Figura 7: Limites municipais e áreas de expansão domiciliar (AED) da região metropolitana de Belém (2000).

Fonte: IBGE (2000). Elaboração do Departamento de Arquitetura e Urbanismo (DAU) (2006).

As modificações entre a realidade de 1991 e a de 2000 foram a base para a nomenclatura de tipos (detalhados nos quadros ao final do 160 
paper). Para a espacialização e a análise dessas informações em mapa, mostrando a configuração feita com os resultados do censo do IBGE em 1991 (Figura 8) e outro com a de 2000 (Figura 9), em que há um nível intrametropolitano, utilizaram-se os dados censitários nas referidas 56 AED. Nota-se que o censo IBGE restringe-se à área urbana dos municípios que compõem a RMB e a sua estrutura urbana, que compreende quatro grandes espaços: a área central, a área de transição, a área de expansão e as ilhas.

Uma análise preliminar da distribuição dos grupos socioocupacionais permite fazer algumas constatações. Em primeiro lugar, verifica-se que há uma divisão social no espaço que opõe dois pólos opostos: "categorias superiores" versus "camadas populares". Em termos quantitativos, observa-se um forte contraste entre as categorias superiores e inferiores, enquanto os tipos médios aproximam-se em termos percentuais das categorias superiores e distanciam-se das categorias inferiores. Em segundo lugar, os três tipos populares, os trabalhadores do comércio e os prestadores de serviços especializados contribuem com percentuais representativos.

Conforme mencionado anteriormente, a fisiografia do atual centro metropolitano teve papel determinante na geração desse quadro, visto que as classes mais abastadas e médias (tipos superior e médio superior) concentravam suas habitações nas cotas mais altas da cidade, ao mesmo tempo que os pobres (tipos operário e popular) ocupavam informalmente as cotas mais baixas do espaço urbano ou as baixadas próximas aos cursos d'água que adentravam a cidade.

A comparação dos mapas das figuras 8 e 9 permite constatar que a área central da primeira légua patrimonial era ocupada por tipos superiores em 1991, situação que se manteve em 2000. Também foi observada a equiparação de categorias que ocupam as áreas urbanas insulares do município de Belém, principalmente as ilhas de Mosqueiro e Caratateua, com os moradores dos municípios onde predomina o rural. É o caso das cinco AED que representam o tipo popular periférico, as quais abrangem os municípios de Benevides e Santa Bárbara do Pará e as regiões ao norte de Ananindeua. Na RMB, em 1991, foi detectada uma concentração de um grupo de profissionais superiores que se reorganiza e se "dilui" no tipo médio em 2000. A inclusão dos demais municípios da RMB em 2000 altera a configuração de um tipo agrícola identificado na região insular de 1991, sendo incorporado como popular periférico em 2000.

Também é marcante a concentração do tipo operário, representado pelas categorias dos trabalhadores do comércio e prestadores de serviços especializados, nos bairros de baixada da primeira légua patrimonial, no entorno do centro metropolitano, bem como nos arredores do centro de Ananindeua, em direção aos lagos do Utinga, do bairro universitário e de todo o bairro do Bengüi. A localização do Bengüi é interessante, porque o bairro representa uma "ilha" no meio do tipo médio superior que se desenvolveu na área de transição da RMB, o que possivelmente expressa 
uma relação de dependência socioeconômica entre esses tipos. As áreas da cidade onde se localizam as AED operárias não são tão valorizadas pelo mercado imobiliário, devido, entre outras razões, à carência de infraestrutura, às limitadas condições de oferta de comércio e serviços e de equipamentos públicos e ao baixo grau de agregação de investimentos nos seus espaços urbanos, o que favorece o acesso dos pobres à moradia nessas áreas, pelo menos quando o acesso ao transporte público é garantido.

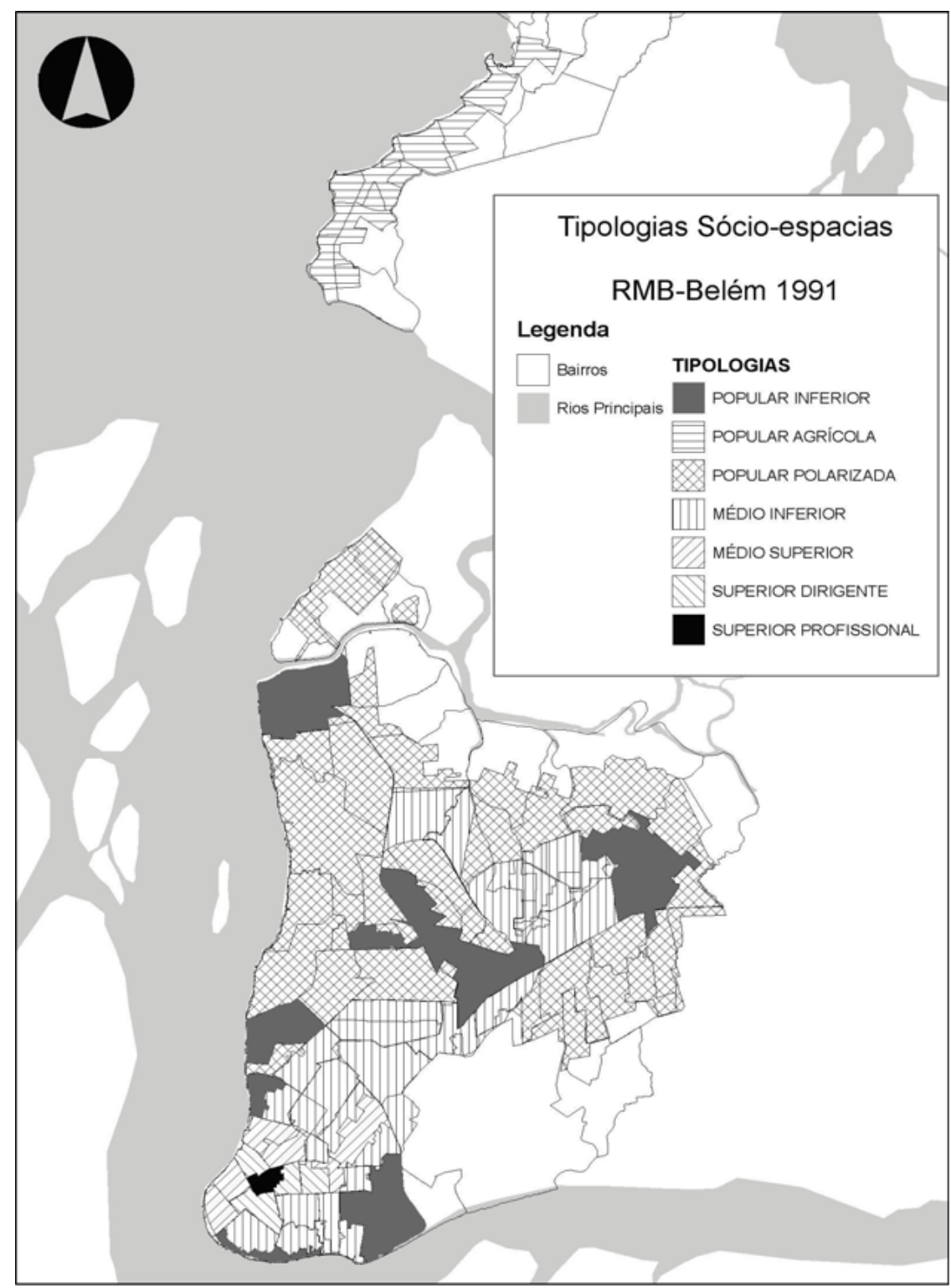

Figura 8: Limites municipais e divisão socioespacial da RMB (1991). Fonte: Dados da Metrodata, processados pelo IPPUR (UFRJ) e pelo DAU (UFPA).

A caracterização do processo histórico de ocupação do território de Belém e de sua região metropolitana é essencial para a compreensão da distribuição espacial dos tipos apresentada acima; o que é reforçado pela comparação da evolução da distribuição dos tipos nos mapas de 162 
1991 e 2000. A conformação atual tem suas origens na segregação socioespacial que remonta ao período da borracha (início do século XX). A segmentação social era clara: a elite era fortemente vinculada às atividades de comércio e representação comercial, sendo ainda constituída por profissionais liberais e pelos donos dos meios de produção; já a classe média era constituída por comerciantes migrantes, oriundos do interior do Estado, que possuíam lojas no centro comercial e moradias em bairros populares, e por funcionários públicos mais bem remunerados que se localizavam nos espaços de transição entre as áreas mais ricas e as populares. A população operária atuava como mão-deobra nos setores de comércio e serviços e de transporte fluvial. Por meio dela, Belém manteve-se historicamente ligada à vida ribeirinha.



Figura 9: Limites municipais e divisão socioespacial da RMB (2000). Fonte: Dados da Metrodata, processados pelo IPPUR (UFRJ) e pelo DAU (UFPA). 
Convém lembrar que houve uma "subdivisão" nos portos na cidade. A orla da baía do Guajará recebeu investimentos de peso, foram construídos portos, que posteriormente seriam assumidos pelo poder público (PENTEADO, 1968); atualmente se encontra fortemente associada ao tipo superior, nos bairros dispostos ao longo dessa orla: Cidade Velha, Campinas, Reduto e Umarizal. Já a orla do rio Guamá foi ocupada gradativamente por portos privados. Aí predomina o tipo operário (mão-de-obra operária), que se estabeleceu sobre os alagados em casas de madeira e palha, originando os bairros do Jurunas, da Condor, do Guamá e da Terra Firme. Nesse processo houve a transposição de soluções de moradia do local de origem da população (interior ribeirinho) para a capital e um distanciamento desse tipo operário das classes urbanas tradicionais (tipo superior), uma vez que a atividade cotidiana da população operária era dissociada das atividades dominadas pelas classes dirigentes (o trabalho em embarcações e portos caracterizava-se por uma sazonalidade incompatível com as exigências do sistema educacional ou do trabalho de escritório), o que retardou o questionamento da segregação socioespacial.

Por outro lado, é clara a predominância do tipo superior na zona central da RMB, que reúne as cinco grandes AED que abrangem os bairros da Cidade Velha, de Batista Campos, de Nazaré, de São Brás, da Campina, do Reduto, do Umarizal e do Marco, ou seja, os bairros com melhor infra-estrutura e com maior concentração de bens, serviços e ofertas de emprego da RMB e das categorias mais expressivas da elite da região. Ao mesmo tempo, o tipo médio é responsável pela estruturação da área de transição da RMB, principalmente nos espaços que contém as cinco AED que englobam os bairros da Marambaia, de Val-de-Cans, do Mangueirão, do Parque Verde e porções do Souza, CurióUtinga e Castanheira, seguidas de uma área que corresponde ao centro de Ananindeua (ao longo da BR-316). Contribuem ainda para essa estruturação as três AED do tipo médio localizadas atrás do centro de Ananindeua, que correspondem aos conjuntos habitacionais (principalmente às Cidades Novas), ao eixo da rodovia Mário Covas e à região de sítios (residências de fim de semana).

O tipo médio requalifica-se entre 1991 e 2000, subdividindo-se e, ao mesmo tempo, transferindo-se da área central para a área de expansão de Belém e para outros municípios. As predominâncias dentro da área central modificam-se. As áreas mais altas mantiveram o padrão de ocupação diferenciado, predominando o tipo superior nos bairros da Cidade Velha, da Campina, do Reduto, de Batista Campos, do Umarizal e em parte dos bairros do Marco, de São Braz. Bairros limítrofes, onde anteriormente predominava a tipologia média inferior, passaram a abrigar os tipos médio superior e médio (Telégrafo, Cremação, Fátima, Canudos e Pedreira). Por outro lado, os tipos populares em 1991 eram restritos à Estrada Nova e aos bairros próximos da desembocadura dos igarapés Tucunduba e Galo. Em 2000 houve uma expansão da área de predominância do tipo popular, que 
passou a ocupar todo o Jurunas, a Condor e o Guamá (bacia da Estrada Nova), toda a Terra Firme e o bairro universitário (bacia do Tucunduba), toda a Sacramenta, o Barreiro, Miramar e a Maracangalha (bacia do Una). Isso significaria um aumento da desigualdade ou da distância social entre bairros dentro da primeira légua patrimonial?

Se em 1991 não existia o tipo popular operário dentro da primeira légua patrimonial de Belém, em 2000, esse tipo seria o predominante nas áreas citadas (nessa ocasião, transformadas em área central da RMB), e ainda haveria enclaves do tipo popular, em áreas que correspondem aos pontos mais estagnados em termos de integração à cidade da área central da RMB (Terra Firme e Barreiro, áreas pouco alteradas por intervenções oficiais de provisão de infra-estrutura até aquela época).

Após a área central, houve grande mudança em um primeiro anel de ocupação, que antes abrigava os tipos populares operário e médio inferior. Em 2000 essa área passou a abrigar o tipo médio superior, avançando ao longo da rodovia Augusto Montenegro. O tipo popular operário aparece ao longo da rodovia Arthur Bernardes e encontra o tipo popular nas adjacências da vila de Icoaraci, único local onde se observa a ocorrência do tipo médio inferior na RMB. No município de Ananindeua, predominava na Cidade Nova e no centro da cidade o tipo médio inferior, em 2000 essas áreas mostraram-se ocupadas pelos tipos médio e médio superior. Nas áreas vizinhas (Tenoné e Coqueiro), o médio inferior e o popular operário deram lugar ao tipo médio, acompanhando a tendência já observada na Cidade Nova. Algumas inversões ocorreram, o tipo popular (Curuçambá) foi substituído pelo popular operário, e essa categoria predomina atualmente ao norte, acompanhando a faixa já existente no município de Belém. A BR-316 é um divisor nesse sentido. Os assentamentos localizados ao sul da rodovia têm condição semelhante nos dois mapas.

A macrodrenagem do igarapé das Almas, localizado em áreas de expansão do centro de Belém, foi o ponto de inflexão no enfrentamento do obstáculo representado pelas baixadas. Outras ações menores foram realizadas em áreas como o Marco e a Pedreira, por meio dos Projetos Cura e Infra Marco, e durante os anos 80 foi obtido o financiamento para a macrodrenagem da bacia do Una, que corresponde a aproximadamente 60\% da área da cidade. Essa intervenção estrutural viabilizou a criação de uma série de ligações entre vias e bairros no interior da primeira légua patrimonial de Belém, tornando essa área ainda mais atraente para a população e principalmente para o mercado imobiliário.

A concepção da macrodrenagem do Una foi fortemente sanitarista, o que é compreensível dada a insalubridade anteriormente observada em muitos dos bairros populares contidos naquela bacia; entretanto o resultado da ação foi o reforço da segregação socioespacial, uma vez que a ação não se restringiu apenas à melhoria das condições sanitárias, alcançou o mercado de terras, com impactos no acesso e na possibilidade de permanência da população mais pobre na área. Do total de domicílios 
da RMB, mais de 123.000 são considerados domicílios adequados do ponto de vista das condições de saneamento, e o restante - cerca de 292.000 ou 70\% - é considerado inadequado. Os maiores percentuais de domicílios inadequados em relação ao total de domicílios encontram-se nos tipos socioocupacionais popular operário, popular e popular periférico, com cerca de 93,43\%, 87,54\% e 87,58\%, respectivamente. Em contrapartida, os índices de domicílios adequados nesses mesmos tipos são muito baixos, cerca de 2,9\%, 4,2\% e 2,9\%, respectivamente. Já o tipo superior apresenta o menor percentual de domicílios inadequados, chegando a 31\% do total de domicílios existentes na RMB (Tabela 7).

Tabela 7: Condições de saneamento no domicílio da RMB por tipo socioocupacional (2000).

\begin{tabular}{|c|c|c|c|c|c|c|}
\hline \multirow{3}{*}{ Tipo } & \multicolumn{4}{|c|}{ Condiçōes de saneamento por domicflio } & \multirow{3}{*}{$\begin{array}{c}\text { Domicflios } \\
\text { Total }\end{array}$} & \multirow{3}{*}{$\begin{array}{c}\text { Inadequadas } \\
\text { Total }\end{array}$} \\
\hline & \multicolumn{2}{|c|}{ Adequadas } & \multicolumn{2}{|c|}{ Inadequadas } & & \\
\hline & Total & Percentual & Total & Percentual & & \\
\hline Superior & 25300,27 & 20,44 & 11856,12 & $4,05 \%$ & 37156,39 & $31,91 \%$ \\
\hline Méctio superior & 27923.53 & 22,56 & 41752,21 & $14,28 \%$ & 69675,74 & $59.92 \%$ \\
\hline Médio & 24256.75 & 19.61 & 31006,24 & $10.60 \%$ & 55273 & $56,10 \%$ \\
\hline Médio inferior & 4569,58 & 3.69 & 13515.42 & $4,62 \%$ & 18085 & $74.73 \%$ \\
\hline Operário & 29244,07 & 23,63 & 80921.54 & $27.67 \%$ & 110165,61 & $73,45 \%$ \\
\hline Popular operário & 3588,68 & 2,9 & 51019,22 & $17,45 \%$ & 54607.9 & $93,43 \%$ \\
\hline Fopular & 5266.66 & 4,26 & 37001,56 & $12.65 \%$ & 42268,22 & $87.54 \%$ \\
\hline Popular periférico & 3595,2 & 2,91 & 25349,09 & $8.67 \%$ & 28944,29 & $87,58 \%$ \\
\hline Total & 123755 & 100 & 292421 & $100,00 \%$ & 416176,2 & $70,26 \%$ \\
\hline
\end{tabular}

Fonte: Metrodata (IBGE, 2000).

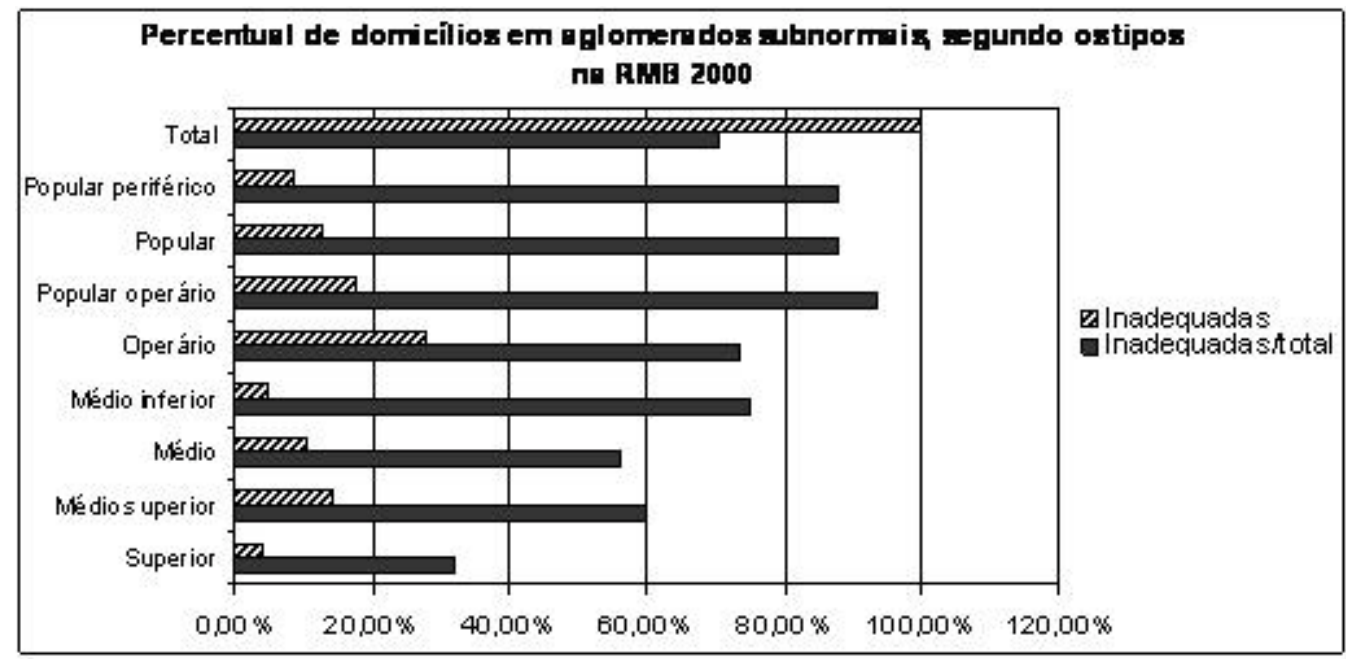

Gráfico 1: Domicílios em aglomerados subnormais na RMB, segundo os tipos socioocupacionais (2000).

Fonte: Metrodata (IBGE, 2000).

As ações de saneamento viabilizaram a pavimentação completa das ruas de bairros internos à primeira légua de Belém. Durante os anos 90, merece destaque o asfaltamento do bairro do Marco e a elevação do 
nível de avenidas importantes, que sofriam alagamentos freqüentes. Assim, ruas como Mundurucus, Alcindo Cacela, Primeiro de Dezembro e Pedro Miranda rapidamente assumiram a condição de subcentros (ver mapa que identifica as avenidas eram centros de bairro, apresentado no item 2). Também foram realizadas ligações viárias estratégicas para a melhoria da mobilidade dentro da primeira légua patrimonial, que articularam as áreas de bairros nobres aos bairros adjacentes, como a ligação entre São Braz e Pedreira, entre Nazaré e Fátima, entre as duas metades do Marco nas imediações do Bosque Rodrigues Alves. Foram construídas pontes importantes que requalificaram o acesso ao aeroporto, como a ponte da avenida Júlio César, que permitiu a sua duplicação, ou a ponte que permitiu a ligação da avenida Tavares Bastos à avenida Pedro Álvares Cabral. Tais ações explicam a mudança ocorrida no padrão de ocupação dos bairros beneficiados, observadas quando da comparação entre os mapas das tipologias de 1991 e de 2000: constata-se a ampliação do tipo superior e a polarização desse tipo com os tipos operário e popular, com significativa redução do tipo médio. Nessa mesma década, foi construída a primeira parte do novo terminal de passageiros do aeroporto de Val-de-Cans, e, a partir de sua avenida de acesso, a avenida Júlio César, foram consolidadas novas ligações com a área de expansão, como a rodovia do Mangueirão, ligação entre o aeroporto e o estádio olímpico. Em extremos opostos, verifica-se a reforma da avenida Visconde de Souza Franco, criada no final dos anos 70 com a citada macrodrenagem do igarapé das Almas, e a construção do canal e avenida Cipriano Santos, em um dos enclaves da tipologia operária remanescentes na primeira légua patrimonial de Belém. A reforma da Doca, como é chamada a primeira avenida, foi a menina-dos-olhos do prefeito da época (autodeclarado "tarado por Doca") e concluiu o projeto do setor imobiliário de transformar aquele novo logradouro no filé mignon do setor imobiliário da cidade. A avenida Visconde de Souza Franco ligou três bairros da cidade, dois dos quais de status historicamente diferenciado na cidade Nazaré e Umarizal - e o antigo bairro industrial do Reduto. Além disso, os investimentos feitos nos bairros de Batista Campos e do Jurunas permitiram ampliar a ocupação das categorias dos tipos superiores para além do bairro de Nazaré.

Já no final da década, a avenida Cipriano Santos prometeu promover a ligação entre o terminal rodoviário e a avenida Perimetral, facilitando o acesso dos servidores das instituições localizadas ao longo da última (Embrapa, UFRA, UFPA, MPEG), porém a não conclusão dos trabalhos de macrodrenagem da bacia do Tucunduba e a má qualidade do serviço de pavimentação comprometeram o resultado da intervenção; a nova avenida degradou-se rapidamente e precisou ter o tráfego de ônibus interrompido, poucos meses após sua inauguração. Essa foi a primeira ação significativa do poder público em área aterrada pelos moradores da bacia do Tucunduba no decorrer de duas décadas, mas, devido à completa desarticulação das 
ações ${ }^{3}$, não foi capaz de reverter as desvantagens existentes. Ocorreu um processo de transformação ao longo da avenida, desencadeado pela melhoria das condições físicas, mais perceptível por conta da precariedade preexistente (as casas estão sendo construídas em alvenaria, e os lotes lindeiros estão sendo aterrados, mantendo-se o alagamento do miolo da quadra), que não se compara ao processo desencadeado em condições de localização mais favoráveis, o que pode ser visto como positivo na perspectiva da população original que se mantém na área. Também foram realizadas intervenções pontuais na bacia da estrada Nova, como a construção do porto da Condor, terminal de passageiros para usuários do transporte fluvial.

Com o tempo, a urbanização acelerada do centro de Belém, acompanhada de grandes obras de infra-estrutura, "expulsou" para as áreas de transição e expansão da RMB diversas concentrações residenciais de baixa renda localizadas nessas baixadas. Mesmo assim, ainda são consideráveis os grupos dessa classe nas proximidades do centro metropolitano. Isso se deve principalmente ao fato de ainda existirem áreas de baixadas, onde os pobres podem ter maior acesso à moradia, ao transporte e aos bens, serviços e ofertas de emprego que o centro consolidado oferece.

A década de 90 contou ainda com diversos marcos da reformulação da organização do município de Belém. Em 1993 foi aprovado o Plano Diretor Urbano de Belém, segundo recomendações da Constituição Federal. Como conseqüência imediata da aprovação do plano, foi criada a Secretaria Municipal de Planejamento e Gestão (SEGEP).

O progressivo aquecimento da dinâmica imobiliária da cidade resultou na demolição de muitas construções produzidas durante o ciclo da borracha, tanto as construídas pelas elites, quanto as construções mais simples (vilas operárias). Isso levou à regulamentação no âmbito municipal do centro histórico e de sua área de entorno e a criação da Fundação Cultural do Município de Belém (FUMBEL) dentro da estrutura administrativa da prefeitura. Passou a haver controle de áreas para verticalização, controle da estrutura física descolada de uma política de desenvolvimento urbano (obsolescência do centro), o que favoreceu a transferência das atividades de comércio e serviços, historicamente concentradas nos bairros da Campina e do Comércio, para os novos eixos criados dentro da primeira légua patrimonial da cidade e facilitou a posterior expansão para núcleos externos, como o Entroncamento e a Cidade Nova.

\footnotetext{
${ }^{3}$ As intervenções a montante do igarapé Tucunduba foram realizadas por ocasião do Projeto Cura, mas não foram objeto de projeto que calculasse os níveis de aterro para garantir as declividades mínimas necessárias para solucionar os problemas de alagamento na área. Em conseqüência, mesmo após a intervenção, a área apresenta problemas durante a estação chuvosa.
} 


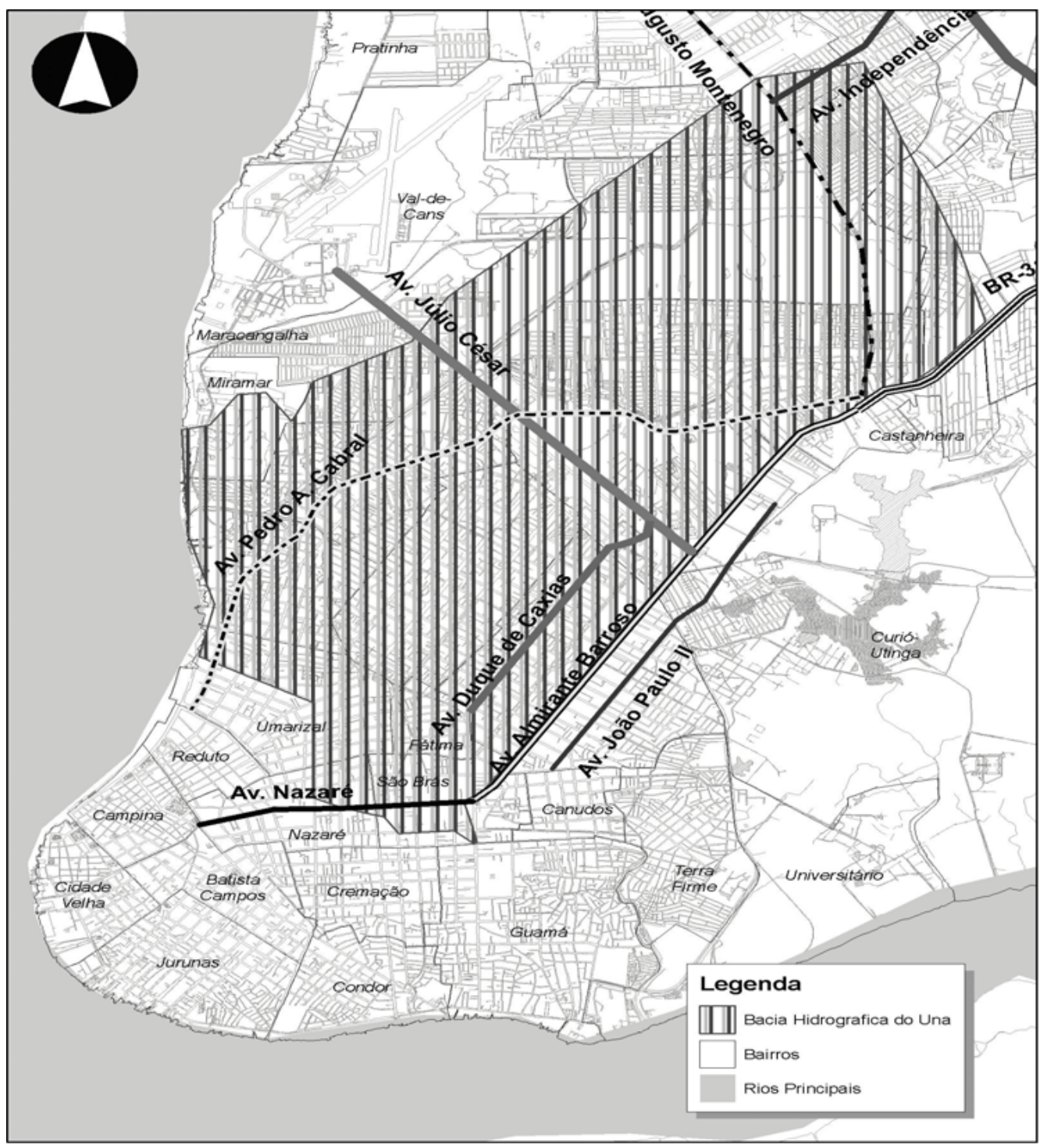

Figura 10: Área de abrangência da macrodrenagem: bacia do Una, avenida Doca de Souza Franco, aeroporto, estádio olímpico, bacia do Tucunduba, porto da Condor e ligação da Cipriano Santos.

\subsection{Empregos: ocorrência e espacialização segundo os tipos socioocupacionais}

O município de Belém dentro do Estado do Pará é um dos que mais emprega, até mesmo por apresentar um dos maiores PIB do Estado. Assim, é pertinente verificar a potencialidade do município no que se refere ao emprego formal. A variável emprego formal é um bom indicativo de potencialidade por algumas razões. A primeira é o efeito psicológico que o emprego formal causa nas pessoas, a idéia de se ter um trabalho seguro atrai um contingente de trabalhadores maior, e, como Belém e a região metropolitana são grandes empregadores, observa-se o deslocamento de uma grande massa populacional para esses centros. 
O segundo fator seriam os efeitos positivos que o emprego formal causa na dinâmica econômica, principalmente no que diz respeito à geração de impostos, ao aumento da renda e, por conseguinte, ao aumento do consumo, gerando assim crescimento econômico.

De acordo com a RAIS, o município de Belém é o que mais emprega no Estado do Pará, pelos valores de participação relativa. Belém abriga 48,19\% dos empregados formais do Estado, o que, somado ao restante da região metropolitana de Belém, alcança 55,89\% dos trabalhadores formais do Estado do Pará (Tabela 8). Tais observações podem ser confirmadas pela análise da migração para a RMB e do movimento pendular do emprego e do estudo para Belém, partindo dos demais municípios da RMB.

Tabela 8: Total de empregos e participação relativa no Estado do Pará por município (2003).

\begin{tabular}{lr|r}
\hline \multicolumn{1}{c|}{ Hunicípio } & Total de empregos & PR \\
\hline Ananindeua & 36.088 & $6.30 \%$ \\
Belém & 275.925 & $48.19 \%$ \\
Benevides & 2.461 & $0.43 \%$ \\
Marituba & 4.737 & $0.83 \%$ \\
Santa Bárbara & 773 & $0.14 \%$ \\
\hline Total & $\mathbf{3 1 9 . 9 8 4}$ & $\mathbf{5 5 . 8 9 \%}$ \\
\hline
\end{tabular}

Fonte: RAIS, 2003.

O município que recebeu o maior número de migrantes de outros municípios do Estado foi Belém (42.514), enquanto Ananindeua foi o que recebeu o maior número de imigrantes de municípios da RMB cerca de 39.600 pessoas. Dos imigrantes que passaram a compor o contingente de pessoas ocupadas, os provenientes de outros estados foram na sua maior parte para o tipo médio superior (25,27\%), seguidos pelo contingente de operários (21,01\%). Tal ocorrência pode ser explicada pela atração que a RMB representa para trabalhadores vindos em sua maioria do Estado do Maranhão. Embora os dados não apontem especificamente esse Estado, há registro da trajetória de pessoal do Estado vizinho chegando por meio da estrada de ferro Carajás, que, após tentar encontrar trabalho nos municípios do Sul do Estado do Pará, vê a RMB como uma segunda alternativa.

Os migrantes intra-estaduais conformam o tipo operário $(27,36 \%)$, seguido do popular operário (18,98\%). Os migrantes do interior tendem, ainda hoje, a considerar vantajosa a transferência para a capital, que significaria maiores possibilidades de acesso a melhores condições de trabalho e a melhores equipamentos públicos, insuficientes no Estado. O tempo de assimilação de novos códigos de comportamento, de novo estilo de vida e de novas soluções de moradia correspondeu ao tempo necessário para a transformação física de áreas originalmente alagáveis, que se 
tornaram bairros populares no decorrer de décadas de trabalho da população, eventualmente complementada pela atuação do poder público.

No interior da RMB, os deslocamentos maiores também estão ligados à conformação do tipo operário (33,03\%), o que reforça a força de atração para a mão-de-obra não qualificaada.

Tabela 9: Migrantes para a RMB por tipo (2000).

\begin{tabular}{|c|c|c|c|c|c|c|c|c|c|}
\hline Categoria & \begin{tabular}{|c|}
$\begin{array}{c}\text { De outros } \\
\text { estados } \\
\text { ou de } \\
\text { outros } \\
\text { países }\end{array}$ \\
\end{tabular} & $\begin{array}{c}\text { \%De } \\
\text { outros } \\
\text { estados }\end{array}$ & $\begin{array}{c}\text { De outros } \\
\text { municípios } \\
\text { do Estado } \\
\text { do Pará }\end{array}$ & \begin{tabular}{|c|}
$\begin{array}{c}\text { \% De } \\
\text { outros } \\
\text { municípios } \\
\text { do Estado } \\
\text { do Pará }\end{array}$ \\
\end{tabular} & $\begin{array}{c}\text { Da regiāo } \\
\text { metropolitana }\end{array}$ & $\begin{array}{l}\text { \% Da regiāo } \\
\text { metropolitana }\end{array}$ & $\begin{array}{l}\text { Origem não } \\
\text { identificada }\end{array}$ & \begin{tabular}{|c|}
$\begin{array}{c}\text { \% Origem } \\
\text { năo } \\
\text { identificada }\end{array}$ \\
\end{tabular} & Total \\
\hline Superior & 5.778 & 17,72 & 4.373 & 6,54 & 152 & 0,28 & 402 & 7,38 & 10.705 \\
\hline $\begin{array}{l}\text { Média } \\
\text { Média }\end{array}$ & 5.197 & 15,94 & 7.565 & 11,32 & 6.868 & 12,57 & 627 & 11,5 & 20.257 \\
\hline $\begin{array}{l}\text { inferior } \\
\text { Média }\end{array}$ & 1.696 & 5,2 & 2.000 & 2,99 & 102 & 0,19 & 145 & 2,67 & 3.944 \\
\hline superior & 8.239 & 25,27 & 8.934 & 13,37 & 2.294 & 4,2 & 765 & 14,04 & 20.233 \\
\hline Operánios & 6.848 & 21,01 & 18.285 & 27,36 & 18.041 & 33,03 & 1.317 & 24,17 & 44.491 \\
\hline Populax & 3.354 & 10,29 & 9.190 & 13,75 & 6.064 & 11,1 & 902 & 16,56 & 19.511 \\
\hline $\begin{array}{l}\text { Popular } \\
\text { operária } \\
\text { Popular }\end{array}$ & 4.747 & 14,56 & 12.687 & 18,98 & 12.772 & 23,38 & 1.150 & 21,1 & 31.356 \\
\hline periférica & 2.521 & 7,73 & 8.173 & 12,23 & 8.476 & 15,52 & 543 & 9,96 & 19.712 \\
\hline Total & 32.603 & 100 & 66.835 & 100 & 54.617 & 100 & 5.449 & 100 & 159.504 \\
\hline
\end{tabular}

Fonte: Metrodata (IBGE, 2000).

É interessante examinar a evolução de bairros como Fátima, Canudos, Jurunas, Cremação, Guamá e Telégrafo, todos vizinhos dos bairros mais ricos. Esses bairros, em que se formaram os primeiros grupos de pobres nascidos em Belém, correspondem às áreas que apresentam tendência de ascensão no que se refere às tipologias socioespaciais. Há casos de transformação mais lenta, como os bairros da Terra Firme e da Sacramenta - ainda hoje preferidos pela população de migrantes oriundos do interior -, que se apresentam como enclaves circundados por bairros populares.

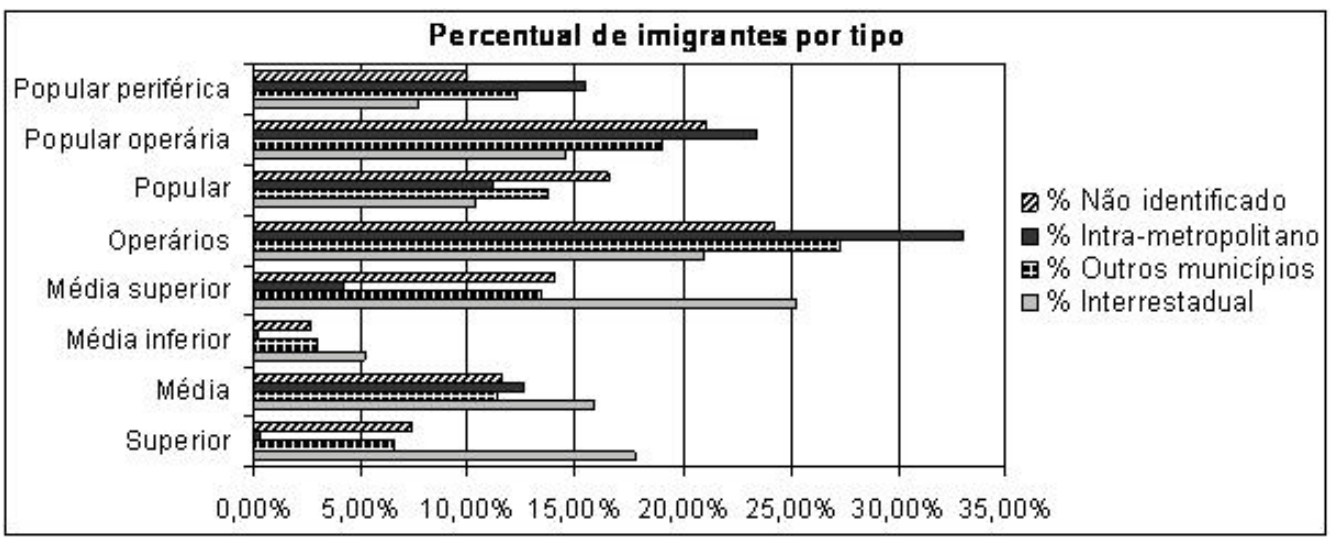

Gráfico 2: Percentuais de imigrantes para a RMB por tipo (2000). Fonte: Metrodata (IBGE, 2000). 
No que diz respeito à mobilidade pendular dentro da RMB, destacase a posição de Belém, município com maior atratividade para o trabalho e o estudo. Dos tipos, o operário é o que mais se desloca para o município-pólo da RMB.

A seguir, vem o tipo popular operário, com o segundo maior número de deslocamentos para o pólo metropolitano e o primeiro em termos de indivíduos que não trabalham no município de residência. Os dados explicam-se pela falta de oportunidades de trabalho nos setores que poderiam localizar-se em outros municípios (Tabela 10).

Tabela 10: Movimento pendular na RMB (2000).

\begin{tabular}{|c|c|c|c|c|c|c|c|c|}
\hline Tipo & $\begin{array}{c}\text { Popnlaçāo } \\
\text { total }>15 \\
\text { anog de } \\
\text { idade }\end{array}$ & $\begin{array}{c}\text { Total } \\
\text { pop. que } \\
\text { trabalh a } \\
\text { on estu da }\end{array}$ & $\begin{array}{l}\text { Pop. trab. } \\
\text { on extu da } \\
\text { fora do } \\
\text { mnnic. de } \\
\text { rexidên cia }\end{array}$ & $\begin{array}{c}\text { x trab. on } \\
\text { extu da } \\
\text { fora do } \\
\text { mnnic. de } \\
\text { rexidên cia }\end{array}$ & $\begin{array}{c}\text { Dirige-se } \\
\text { ao mnnic. } \\
\text { pólo para } \\
\text { trab. on } \\
\text { extn do }\end{array}$ & $\begin{array}{c}\text { \% dirige-ze } \\
\text { ao mnnic. } \\
\text { pólo }\end{array}$ & \begin{tabular}{|c|} 
Degl a \\
ontro \\
mnnicftotal \\
trab on \\
extn da
\end{tabular} & $\begin{array}{c}\text { Degl ao } \\
\text { póloftotal } \\
\text { trab on } \\
\text { estu da }\end{array}$ \\
\hline Superior & 117.026 & 80.394 & 1.759 & $1,87 \%$ & 0 & $0.00 \%$ & 2,2 & 0 \\
\hline Mécio & 180.537 & 119.621 & 21.358 & $22,66 \%$ & 18.643 & $25,11 \%$ & 18 & 16 \\
\hline \multicolumn{9}{|l|}{ Mécio } \\
\hline inferior & 54.486 & 34.286 & 698 & $0.74 \%$ & 0 & $0.00 \%$ & 2 & 0 \\
\hline \multicolumn{9}{|l|}{ Mécio } \\
\hline superior & 216.059 & 143.453 & 6.470 & $5.86 \%$ & 3.674 & $4,95 \%$ & 4,5 & 56.8 \\
\hline Operário & 342.602 & 227.212 & 34.278 & $36,36 \%$ & 29.674 & $39,96 \%$ & 15,1 & 86,6 \\
\hline Fopular & 120.630 & 79.787 & 6.911 & $7,33 \%$ & 5.469 & $7,37 \%$ & 8.7 & 79,1 \\
\hline \multicolumn{9}{|l|}{ Popular } \\
\hline operário & 148.975 & 92.698 & 15.824 & $16,79 \%$ & 11.545 & $15,55 \%$ & 17,1 & 73 \\
\hline \multicolumn{9}{|l|}{ Popular } \\
\hline periférico & 78.715 & 49.848 & 6.953 & $7,39 \%$ & 5.246 & $7,07 \%$ & 14 & 75,3 \\
\hline Total & 1.259 .030 & 827.299 & 94.260 & $100,00 \%$ & 74.252 & $100,00 \%$ & $11,39 \%$ & $8,98 \%$ \\
\hline
\end{tabular}

Fonte: Metrodata (IBGE, 2000).

Um dos motivos pelos quais Belém não apresenta um índice de concentração normalizado alto em alguns setores que sabidamente são fortes, como o de comércio e serviços, seria o fato de a cidade não apresentar mais um nível de atração tão forte quanto outras cidades do interior do Estado, como Barcarena e Parauapebas, em que foram implantados projetos de exploração mineral. Belém tornou-se uma cidade saturada quanto à geração de emprego e, justamente por isso, atualmente enfrenta o problema do crescimento cada vez maior do mercado informal. Destaca-se em Belém o setor de serviços, que ocupa 65,49\% da massa de trabalhadores formais, do comércio, com 18,44\%, seguido da indústria (5,27\%) e dos transportes (3,74\%) (Tabela 11).

Dessas quatro atividades, somente a indústria não faz parte do complexo turístico, que hoje é uma forte potencialidade econômica do município, tanto na dinamização da economia como também na geração de emprego e renda.

A evidência da importância que o complexo turístico ganha na dinâmica da RMB fica caracterizada principalmente com algumas políticas públicas que são direcionadas para o referido setor, ganhando destaque assim nessa economia urbana. 
Tabela 11: Distribuição de empregos por setores no município de Belém (2003).

\begin{tabular}{lrc}
\hline \multicolumn{1}{c}{ Setor } & N. $^{-0}$ & \% \\
\hline Agricultura & 126 & 0.05 \\
Pecuária & 1992 & 0.72 \\
Floresta & 120 & 0.04 \\
Indústria & 14541 & 5.27 \\
Madeira e mobiliário & 4949 & 1.79 \\
Agroindústria vegetal & 5352 & 1.94 \\
Agroindústria animal & 573 & 0.21 \\
Energia & 1857 & 0.67 \\
Comércio & 50874 & 18.44 \\
Transportes & 10317 & 3.74 \\
Instituiçōes financeiras & 4527 & 1.64 \\
Serviços & 180697 & 65.49 \\
\hline \multicolumn{1}{c}{ Total } & $\mathbf{2 7 5 9 2 5}$ & $\mathbf{1 0 0 . 0 0}$ \\
\hline
\end{tabular}

Fonte: RAIS, 2003.

\section{Considerações finais}

Embora os dados aqui analisados ofereçam um panorama da situação socioeconômica e espacial da RMB, alguns aspectos das análises estão distorcidos, devido à não inclusão das porções rurais dos municípios. É possível, porém, identificar algumas especificidades. Dificuldades decorrentes do poder aquisitivo da população belenense estariam associadas a problemas ligados ao acesso à habitação e a disfunções no mercado imobiliário, o que pode estar levando camadas inferiores a ocupar os espaços antes ocupados pelas camadas médias. A situação socioocupacional em Belém no período de tempo considerado nas análises confirma a supremacia do setor terciário. É evidente a baixa representatividade dos setores superiores e a relativa homogeneidade da participação de categorias operárias em todos os tipos. O aumento populacional em torno do município de Belém, onde tradicionalmente se concentram empregos e serviços disponíveis para a população da região metropolitana, acelerou-se com a chegada de pessoas vindas de outros locais em busca dos serviços de saúde e de educação. Além disso, a economia da área baseia-se na prestação de serviços necessários para o funcionamento de projetos econômicos no restante da região.

Um panorama geral dos municípios constituintes da RMB mostra uma alta concentração de população em Belém, cada vez mais localizada na direção do vetor de crescimento de Ananindeua, e uma transformação do solo rural em urbano nos demais municípios, principalmente em Ananindeua e Benevides. A dinâmica de crescimento fez com que Ananindeua superasse em população o município de Santarém, até então o segundo município mais populoso do Estado. 
As transformações nas estruturas de trabalho mostram um aumento expressivo das atividades informais em relação às formais. Diferentemente de outras cidades, onde o emprego informal está ligado a estabelecimentos industriais, na RMB, pela expressividade do terciário e pela dependência da indústria do pólo hegemônico do Sul e Sudeste, o trabalho informal está concentrado no setor de serviços e nas ocupações institucionais. Daí a existência de locais com grande concentração de atividades comerciais e independentemente do status residencial em questão. Assim, considerando-se os baixos níveis de renda da população, é evidente que as condições de vida não têm melhorado, e não há expectativa de melhora. Porém, outros estudos devem ser feitos, porque há uma série de relações sociais que ultrapassam as questões colocadas de forma quantitativa. Trata-se de arranjos sociais que conseguem em grande medida compensar os níveis de pobreza. Destacam-se as soluções baseadas na solidariedade entre os vários grupos sociais, e outras medidas incluídas na informalidade, como o transporte e o acesso ao abastecimento alimentar.

Mesmo sem esgotar as possibilidades de análise, os pontos citados acima servem como primeira abordagem das tendências que poderão ser exploradas com base nos dados a serem processados para a região metropolitana de Belém. Levando-se em conta conclusões já obtidas sobre os efeitos da globalização e as modificações causadas pela pósindustrialização, o estudo de Belém revela uma situação de transitoriedade no que se refere aos reflexos das transformações produtivas ocorridas no período analisado. Pelos resultados do desempenho industrial e pela dependência existente em relação ao pólo hegemônico do Sul e Sudeste, os reflexos das modificações detectadas nos paradigmas da pós-industrialização e aplicáveis a cidades globais, poderão ser testados em um espaço fora do circuito maior do capitalismo. Problemas de várias ordens poderão ser relacionados, tendo em vista, por exemplo, a questão ambiental. Com base nos dados sobre a maior metrópole da região, será possível determinar o papel do urbano na exploração econômica da Amazônia. 


\section{REFERÊNCIAS}

BELÉM. Prefeitura Municipal de Belém. Mensagem à Câmara Municipal. 1987.

BELÉM. Prefeitura Municipal de Belém. Coordenadoria Geral e de Planejamento. Diagnóstico do Plano Diretor de Belém. Não publicado, 1992.

BORGES, Maria Vitória Paracampo. Cidadania e direito de morar: a prática de ocupações coletivas e o movimento de posseiros de Jaderlândia, Ananindeua, Pará. 1992. 363 f. Dissertação (Mestrado em Planejamento do Desenvolvimento) - Núcleo de Altos Estudos Amazônicos, Universidade Federal do Pará, Belém, 1992.

BOURDIEU, Pierre. Razões práticas: sobre a teoria da ação. Campinas: Papirus, 1997.

CARDOSO, Ana Cláudia Duarte. The Alternative Space: Informal Settlements and Life Chances in Belém, Brazil. 2002. Tese (Doutorado em Arquitetura) - Oxford Brookes University, Oxford, 2002.

CHENU. Antoine e TABARD, Nicole ( 1993) Les transformations socioprofissionelles du territoire français, 1982-1900 Population 6, p $1735-1770$

INSTITUTO BRASILEIRO DE GEOGRAFIA E ESTATÍSTICA (IBGE). Censo Demográfico 1991: documentação dos microdados da amostra. Rio de Janeiro: IBGE, 1992.

INSTITUTO BRASILEIRO DE GEOGRAFIA E ESTATÍSTICA IBGE. Censo Demográfico 2000: documentação dosmicrodados da amostra. Rio de Janeiro: IBGE, 2002.

INSTITUTO DE PESQUISAS ECONÔMICAS APLICADAS (IPEA). Gestão do uso do solo e disfunções do crescimento urbano. Instrumentos de planejamento e gestão urbana: Belém, Natal e Recife. Brasília, DF, 2002.

MENDONÇA, Jupira G. Segregação e mobilidade residencial na região metropolitana de Belo Horizonte. Rio de Janeiro, 2002. Tese (Doutorado em Planejamento Urbano e Regional) - UFRJ/IPPUR.

PENTEADO, Antonio Rocha. Estudo de geografia urbana de Belém. Belém: UFPA, 1968. 
PRETECEILLE, Edmond. Division sociale et globalisation; le cas de la métropole parisienne. Sociétés Contemporaines, p. 22-23, 1995.

PNUD. Relatório sobre o desenvolvimento humano no Brasil. Rio de Janeiro: IPEA; Brasília: PNUD, 2001.

RIBEIRO, Luiz César de Queiroz. Cidade desigual ou cidade partida? Tendências da metrópole do Rio de Janeiro. In: RIBEIRO, Luiz César de Queiroz (Org.). O futuro das metrópoles: desigualdades e governabilidade. Rio de Janeiro: Revan; FASE, p. 63-98, 2000.

RIBEIRO, Luiz Cesar de Queiroz; LAGO, Luciana Corrêa do. O espaço social das grandes metrópoles brasileiras: Rio de Janeiro, São Paulo e Belo Horizonte. Revista Brasileira de Estudos Urbanos e Regionais, Recife, ANPUR, n. 3, p. 111-130, set. 2000.

SARGES, Maria de Nazaré. Belém: riqueza produzindo a Belle Époque (1870-1912). Belém: Paka-Tatu, v. 01, 152 p. 2000.

TRINDADE JÚNIOR, Saint Clair. A cidade dispersa, os novos espaços de assentamentos em Belém e a reestruturação metropolitana. São Paulo. Tese (Doutorado em Geografia Humana) - Faculdade de Filosofia e Ciências Humanas, Universidade de São Paulo, São Paulo, 1998. 
Tabela 12: Distribuição das categorias socioocupacionais pelos tipos (números absolutos) (1991).

\begin{tabular}{|c|c|c|c|c|c|c|c|c|}
\hline \multirow{2}{*}{$\begin{array}{c}\text { CATEGORIAS } \\
\text { SOCIOOCUPACIORAIS }\end{array}$} & \multicolumn{8}{|c|}{ TIPOS } \\
\hline & $\mathbf{s}$ & SP & $\mathbf{Y}$ & II & PO & $\mathbf{P}$ & PP & TG \\
\hline Ocupaçōes agricolas & 302 & $\mathbf{2 6}$ & 463 & 2.374 & 3.654 & 2.451 & 696 & 9.966 \\
\hline Grandes empresários & 861 & 192 & 705 & 1.001 & 130 & 123 & 6 & 3.018 \\
\hline Dirigentes do setor público & 192 & 62 & 198 & 277 & 39 & 48 & 6 & 822 \\
\hline Dirigentes do setor privado & 172 & 21 & 156 & 61 & 35 & 0 & 0 & 423 \\
\hline Profissionais liberais & 195 & 109 & 149 & 124 & 25 & 15 & 0 & 617 \\
\hline Elite dirigente & 1.420 & 384 & 1.188 & 1.463 & 227 & 186 & 12 & 4.880 \\
\hline Profissionais autónomos & 276 & 86 & 511 & 926 & 222 & 175 & 0 & 2.196 \\
\hline Empregados de nivel superior & 3.535 & 905 & 4.112 & 9.529 & 2.050 & 1.150 & 35 & 21.296 \\
\hline Elite intelectual & 3.811 & 991 & 4.623 & 10.455 & 2.252 & 1.325 & 35 & 23.492 \\
\hline \multicolumn{9}{|l|}{ Pequenos empregadores } \\
\hline urbanos & 956 & 200 & 1.260 & 5.162 & 2.020 & 692 & 88 & 10.378 \\
\hline Comerciantes por conta própria & 688 & 73 & 1.450 & 11.930 & 5.040 & 2.924 & 338 & 25.445 \\
\hline Pequena burguesia & 1.644 & 273 & 2.710 & 17.092 & 8.060 & 3.616 & 426 & 33.821 \\
\hline Empregados escritórios & 1.885 & 209 & 3.624 & 20.803 & 7.346 & 2.688 & 91 & 35.646 \\
\hline Empregados supervisio & 1.679 & 208 & 3.005 & 11.154 & 3.395 & 1.665 & 54 & 21.158 \\
\hline Empregados técnicos & 688 & 79 & 1.197 & 5.251 & 1.528 & 940 & 15 & 9.698 \\
\hline Empregados gáde e educaçāo & 1.021 & 97 & 2.042 & 10.707 & 4.129 & 1.810 & 240 & 20.046 \\
\hline \multicolumn{9}{|l|}{ Empregados segurança pública, } \\
\hline juatiça & 198 & 30 & 623 & 6.458 & 2.627 & 1.160 & 65 & 11.161 \\
\hline Setores médios & 5.471 & 623 & 10.491 & 54.373 & 19.025 & 8.261 & 465 & 98.709 \\
\hline Operários da indúatria moderna & 38 & 6 & 310 & 4.008 & 2.655 & 1.300 & 51 & 8.368 \\
\hline \multicolumn{9}{|l|}{ Operários da indúatria } \\
\hline tradicional & 85 & 9 & 352 & 8.044 & 7.420 & 3.811 & 213 & 19.934 \\
\hline \multicolumn{9}{|l|}{ Operários zerviços auxiliares da } \\
\hline indúatria & 313 & 8 & 817 & 12.765 & 6.346 & 3.622 & 235 & 24.106 \\
\hline Operários da conatruçāo civil & 85 & 11 & 577 & 11.385 & 10.842 & 8.635 & 1.335 & 32.869 \\
\hline Artecios & 230 & 13 & 536 & 4.219 & 2.485 & 1.033 & 52 & 8.568 \\
\hline \multicolumn{9}{|l|}{ Operariado do setor } \\
\hline secundário & 751 & 47 & 2.592 & 40.421 & 29.748 & 18.399 & 1.887 & 93.845 \\
\hline Operários do comércio & 806 & 185 & 1.744 & 14.288 & 6.575 & 2.926 & 68 & 26.590 \\
\hline \multicolumn{9}{|l|}{ Operários de serviços } \\
\hline especializados & 353 & 60 & 1.363 & 18.899 & 10.135 & 4.712 & 219 & 35.741 \\
\hline \multicolumn{9}{|l|}{ Operários de zerviços nāo } \\
\hline especializados & 274 & 15 & 816 & 13.143 & 8.852 & 4.607 & 360 & 28.067 \\
\hline terciário & 1.433 & 258 & 3.923 & 46.350 & 25.562 & 12.245 & 647 & 90.398 \\
\hline Empregados doméaticos & 2.824 & 574 & 3.359 & 17.059 & 9.551 & 6.114 & 581 & 40.042 \\
\hline Biscateiros & 253 & 0 & 584 & 11.957 & 9.025 & 4.077 & 223 & 26.120 \\
\hline Ambulantes & 6 & 0 & 46 & 923 & 702 & 349 & 38 & 2.064 \\
\hline \multicolumn{9}{|l|}{ Trabalhadores da } \\
\hline sobrerirencia & 3.083 & 574 & 3.969 & 29.939 & 19.279 & 10.540 & 842 & 68.226 \\
\hline TOTAL. & 17.915 & 3.176 & 29.959 & 202.447 & 107.807 & 57.023 & 5.010 & 423.357 \\
\hline
\end{tabular}

Fonte: IBGE. Censo Demográfico, 2000. Elaboração do Departamento de Arquitetura e Urbanismo (DAU) da UFPA (2006).

S: Superior; SP: Superior Profissional; M: Médio; MI: Médio inferior; PO: Popular operário; P: Popular; PP: Popular Periférico; TG: Total geral. 
Tabela 13: Composição dos tipos (densidade) (1991).

\begin{tabular}{|c|c|c|c|c|c|c|c|c|}
\hline \multirow{2}{*}{$\begin{array}{c}\text { CATEGORIAS } \\
\text { SOCIOOCUPACIOHAIS }\end{array}$} & \multicolumn{8}{|c|}{ TIPOS } \\
\hline & $\mathbf{s}$ & SP & $\mathbf{4}$ & MI & Po & $\mathbf{P}$ & $\mathbf{P P}$ & TG \\
\hline Ocupaçōes agrícolas & 0,08 & 0,12 & 0,23 & 0,19 & 0,83 & 0,10 & 0,05 & 0,15 \\
\hline Grandes empresúrios & 0,08 & 0,12 & 0,23 & 0,19 & 0,83 & 0,10 & 0,05 & 0,15 \\
\hline Dirigentes do setor público & 0,03 & 0,18 & 0,01 & 0,01 & 0,01 & 0,28 & 0,33 & 0,04 \\
\hline Dirigentes do stor privado & 0,01 & 0,05 & 0,00 & 0,00 & 0,01 & 0,06 & 0,11 & 0,01 \\
\hline Frofissionais liberais & 0,00 & 0,03 & 0,00 & 0,00 & 0,00 & 0,06 & 0,04 & 0,01 \\
\hline Elite dirigente & 0,00 & 0,04 & 0,00 & 0,00 & 0,00 & 0,06 & 0,19 & 0,01 \\
\hline Profissionais autónomos & 0,05 & 0,30 & 0,02 & 0,01 & 0,01 & 0,46 & 0,67 & 0,07 \\
\hline Empregados de nivel superior & 0,03 & 0,13 & 0,02 & 0,01 & 0,00 & 0,09 & 0,15 & 0,03 \\
\hline Elite intelectual & 0,32 & 1,04 & 0,11 & 0,11 & 0,04 & 1,15 & 1,58 & 0,31 \\
\hline \multicolumn{9}{|l|}{ Fequenos empregadores } \\
\hline urbanos & 0,35 & 1,16 & 0,13 & 0,12 & 0,04 & 1,24 & 1,73 & 0,34 \\
\hline Comerciantes por conta propria & 0,17 & 0,32 & 0,07 & 0,10 & 0,10 & 0,31 & 0,35 & 0,15 \\
\hline Pequena burguesia & 0,40 & 0,37 & 0,28 & 0,31 & 0,40 & 0,22 & 0,13 & 0,34 \\
\hline Empregados escritórios & 0,57 & 0,68 & 0,34 & 0,42 & 0,51 & 0,53 & 0,48 & 0,50 \\
\hline Empregados supervił̄o & 0,69 & 0,91 & 0,26 & 0,38 & 0,11 & 0,61 & 0,36 & 0,54 \\
\hline Empregados técnicos & 0,37 & 0,76 & 0,16 & 0,18 & 0,06 & 0,54 & 0,36 & 0,31 \\
\hline Empregados súde e educaçāo & 0,18 & 0,30 & 0,09 & 0,08 & 0,02 & 0,22 & 0,14 & 0,14 \\
\hline \multicolumn{9}{|l|}{ Empregados æeguranģa pública, } \\
\hline justiça & 0,36 & 0,51 & 0,17 & 0,21 & 0,29 & 0,33 & 0,17 & 0,29 \\
\hline Setores médios & 0,22 & 0,16 & 0,11 & 0,14 & 0,08 & 0,06 & 0,05 & 0,16 \\
\hline Operários da indúatria moderna & 1,82 & 2,64 & 0,78 & 0,99 & 0,55 & 1,77 & 1,09 & 1,45 \\
\hline \multicolumn{9}{|l|}{ Operários da indúatria } \\
\hline tradicional & 0,13 & 0,08 & 0,12 & 0,14 & 0,06 & 0,01 & 0,01 & 0,12 \\
\hline \multicolumn{9}{|l|}{ Opeńrios ærviços auxiliares da } \\
\hline indúatria & 0,27 & 0,09 & 0,36 & 0,38 & 0,25 & 0,03 & 0,02 & 0,29 \\
\hline Operários da conatruģäo civil & 0,43 & 0,21 & 0,34 & 0,33 & 0,28 & 0,10 & 0,01 & 0,35 \\
\hline Artecios & 0,38 & 0,15 & 0,82 & 0,56 & 1,59 & 0,03 & 0,02 & 0,48 \\
\hline \multicolumn{9}{|l|}{ Operariado do setor } \\
\hline secundário & 0,14 & 0,14 & 0,10 & 0,13 & 0,06 & 0,07 & 0,02 & 0,13 \\
\hline Operários do comércio & 1,35 & 0,65 & 1,75 & 1,54 & 2,24 & 0,24 & 0,08 & 1,38 \\
\hline \multicolumn{9}{|l|}{ Operários de gervicos } \\
\hline especializados & 0,48 & 0,44 & 0,28 & 0,34 & 0,08 & 0,26 & 0,32 & 0,39 \\
\hline \multicolumn{9}{|l|}{ Operários de zerviços näo } \\
\hline especializados & 0,63 & 0,34 & 0,45 & 0,53 & 0,26 & 0,11 & 0,10 & 0,52 \\
\hline Operariado do setor & 0,44 & 0,21 & $\mathbf{0 , 4 4}$ & 0,46 & 0,43 & 0,09 & 0,03 & 0,41 \\
\hline Empregados domésticos & 1,55 & 0,99 & 1,16 & 1,33 & 0,77 & 0,46 & 0,45 & 1,32 \\
\hline Biscateiros & 0,57 & 0,84 & 0,58 & 0,50 & 0,69 & 0,92 & 1,00 & 0,59 \\
\hline Ambulantes & 0,40 & 0,15 & 0,39 & 0,47 & 0,26 & 0,08 & 0,00 & 0,38 \\
\hline \multicolumn{9}{|l|}{ Trabalhadores da } \\
\hline sobreqirência & 0,03 & 0,01 & 0,03 & 0,04 & 0,05 & 0,00 & 0,00 & 0,03 \\
\hline TOTAL & 1,00 & 1,00 & 1,00 & 1,00 & 1,00 & 1,00 & 1,00 & 1,00 \\
\hline
\end{tabular}

Fonte: IBGE. Censo Demográfico, 2000. Elaboração do Departamento de Arquitetura e Urbanismo (DAU) da UFPA (2006).

S: Superior; SP: Superior Profissional; M: Médio; MI: Médio inferior; PO: Popular operário; P: Popular; PP: Popular Periférico; TG: Total geral. 
Tabela 14: Distribuição das categorias socioocupacionais pelos tipos (\%) (1991).

\begin{tabular}{|c|c|c|c|c|c|c|c|c|}
\hline \multirow{2}{*}{$\begin{array}{c}\text { CATEGORIAS } \\
\text { SOCIOOCUPACIOHAIS }\end{array}$} & \multicolumn{8}{|c|}{ TIPOS } \\
\hline & $\mathbf{s}$ & SP & $\mathbf{Y}$ & YI & PO & $\mathbf{P}$ & PP & TG \\
\hline Ocupaçōes agricolas & $23.8 \%$ & $4,6 \%$ & $24,6 \%$ & $36.7 x$ & $7.0 \%$ & $3.0 \%$ & $0,3 \times$ & $100,0 \%$ \\
\hline Grandes emprezários & $33,2 \%$ & $23,4 \%$ & $41 \%$ & $43 \%$ & $0.2 \%$ & $285 \%$ & $5,4 \%$ & $100,0 \%$ \\
\hline Dirigentes do setor público & $33.7 \%$ & $24,1 \%$ & $5,8 \%$ & $4,7 \%$ & $0.7 \%$ & $23,4 \%$ & $7.5 \%$ & $100,0 \%$ \\
\hline Dirigentes do setor privado & $14,4 \%$ & $32,2 \%$ & $0,0 \%$ & $7.8 \%$ & $0,0 \%$ & $40.7 \%$ & $5,0 \%$ & $100,0 \%$ \\
\hline Profissionais liberais & $20.1 \%$ & $24,1 \%$ & $2,4 \%$ & $41 \%$ & $0,0 \%$ & $31,6 \%$ & $17,7 \%$ & $100,0 \%$ \\
\hline Elite dirigente & $30,0 \%$ & $24,3 x$ & $3.8 \%$ & $4.7 x$ & $0.2 x$ & $29.1 \%$ & $7.9 x$ & $100,0 \%$ \\
\hline Profissionais autônomos & $42,2 \%$ & $23,3 \%$ & $80 \%$ & $10,1 \%$ & $0,0 \%$ & $12,6 \%$ & $3,9 \%$ & $100,0 \%$ \\
\hline Empregados de nivel superior & $44.7 \%$ & $19,3 \%$ & $5,4 \%$ & $9,5 \%$ & $0.2 \%$ & $16,6 \%$ & $4,2 \%$ & $100,0 \%$ \\
\hline Elite intelectual & $44.5 \%$ & $19.7 \%$ & $5.6 \%$ & $9.6 \%$ & $\mathbf{0 . 1 \%}$ & $16.2 \%$ & $4.2 x$ & $100,0 \%$ \\
\hline \multicolumn{9}{|l|}{ Pequenos empregadores } \\
\hline urbanos & $49.7 \%$ & $12,1 \%$ & $5.7 \%$ & $19,5 \%$ & $0,8 \%$ & $9,2 \%$ & $1.9 \%$ & $100,0 \%$ \\
\hline Comerciantes por conta propria & $50,9 \%$ & $5,2 \%$ & $12,5 \%$ & $25,8 \%$ & $1,4 \%$ & $2,9 \%$ & $0,3 \%$ & $100,0 \%$ \\
\hline Pequena burgue sia & $50,5 \%$ & $8.0 \%$ & $10,7 \%$ & $23.8 \%$ & $1.5 \%$ & $4.9 \%$ & $0,8 \%$ & $100,0 \%$ \\
\hline Empregados escritórios & $5 \overline{5}, 8 \%$ & $9,9 \%$ & $7,3 \%$ & $20,0 \%$ & $0.2 \%$ & $5,1 \%$ & $0,6 \%$ & $100,0 \%$ \\
\hline Empregados supervisīo & $52,7 \%$ & $14,2 \%$ & $7,9 \%$ & $15,0 \%$ & $0,3 \%$ & $7,9 \%$ & $1,0 \%$ & $100,0 \%$ \\
\hline Empregados técnicos & $54,1 \%$ & $12,3 \%$ & $9.7 \%$ & $15,8 \%$ & $0.2 \%$ & $7,1 \%$ & $0.8 \%$ & $100,0 \%$ \\
\hline Empregados aúde e educaçäo & $53,4 \%$ & $10,2 \%$ & $9,0 \%$ & $20,6 \%$ & $1,2 \%$ & $5,1 \%$ & $0,5 \%$ & $100,0 \%$ \\
\hline \multicolumn{9}{|l|}{ Empregados aggurança pública, } \\
\hline juatiça & $57,9 \%$ & $5,6 \%$ & $10,4 \%$ & $23,5 \%$ & $0,6 \%$ & $1,8 \%$ & $0,3 \%$ & $100,0 \%$ \\
\hline Setores médios & $55.1 \%$ & $10.6 \%$ & $8.4 \%$ & $19.3 \%$ & $0.5 \%$ & $5.5 \%$ & $0,6 \%$ & $100.0 \%$ \\
\hline Operários da indúatria moderna & $47,9 \%$ & $3.7 \%$ & $15.5 \%$ & $31,7 \%$ & $0.6 \%$ & $0,5 \%$ & $0.1 \%$ & $100,0 \%$ \\
\hline \multicolumn{9}{|l|}{ Operários da indúatria } \\
\hline tradicional & $40,4 \%$ & $1,8 \%$ & $19.1 \%$ & $37.2 \%$ & $1,1 \%$ & $0,4 \%$ & $0,0 \%$ & $100,0 \%$ \\
\hline \multicolumn{9}{|l|}{ Operários zerviços auxiliares da } \\
\hline indúatria & $53,0 \%$ & $3.4 \%$ & $15,0 \%$ & $25,3 \%$ & $1,0 \%$ & $1,3 \%$ & $0,0 \%$ & $100,0 \%$ \\
\hline Operários da conat ruçāo civil & $34,6 \%$ & $1,8 \%$ & $25,3 \%$ & $35,0 \%$ & $41 \%$ & $0,3 \%$ & $0,0 \%$ & $100,0 \%$ \\
\hline Artecios & $49,2 \%$ & $5,3 \%$ & $12,1 \%$ & $29,0 \%$ & $0,6 \%$ & $2.7 \%$ & $0,2 \%$ & $100,0 \%$ \\
\hline \multicolumn{9}{|l|}{ Operariado do setor } \\
\hline secundário & $43.1 \%$ & $2.8 \%$ & $19.6 \%$ & $31.7 \%$ & $2.0 \%$ & $0.8 \%$ & $0,1 \times$ & $100,0 \%$ \\
\hline Operários do comércio & $53.7 \%$ & $5,6 \%$ & $11,0 \%$ & $24,7 \%$ & $0,3 \%$ & $3,0 \%$ & $0,7 \%$ & $100,0 \%$ \\
\hline \multicolumn{9}{|l|}{ Operários de serviços } \\
\hline especializados & $52,9 \%$ & $3,8 \%$ & $13,2 \%$ & $28,4 \%$ & $0.6 \%$ & $1,0 \%$ & $0.2 \%$ & $100,0 \%$ \\
\hline \multicolumn{9}{|l|}{ Operários de æerviços näo } \\
\hline especializados & $4 \overline{6}, 8 \%$ & $2,9 \%$ & $15,4 \%$ & $31,5 \%$ & $1,3 \%$ & $1,0 \%$ & $0,1 \%$ & $100,0 \%$ \\
\hline \multicolumn{9}{|l|}{ Operariado do setor } \\
\hline terciário & $51.3 \%$ & $4.3 \%$ & $13.5 \%$ & $28.3 x$ & $0.7 x$ & $1.6 \%$ & $0.3 \%$ & $100.0 \%$ \\
\hline Empregados domésticos & $42,6 \%$ & $83 \%$ & $15,3 \%$ & $25,9 \%$ & $1,5 \%$ & $7,1 \%$ & $1,4 \%$ & $100,0 \%$ \\
\hline Biscateiros & $45,8 \%$ & $2,2 \%$ & $15,6 \%$ & $34,6 \%$ & $0.9 \%$ & $1,0 \%$ & $0,0 \%$ & $100,0 \%$ \\
\hline Ambulantes & $44.7 \%$ & $2,2 \%$ & $16,9 \%$ & $34,0 \%$ & $1,8 \%$ & $0,3 \%$ & $0,0 \%$ & $100,0 \%$ \\
\hline \multicolumn{9}{|l|}{ Trabalhadores da } \\
\hline sobrerirência & $43.9 \%$ & $5.8 \%$ & 15. $4 \%$ & $28,5 \%$ & $1.2 \%$ & $4.5 \%$ & $0.8 \%$ & $100,0 \%$ \\
\hline TOTAI. & $47.8 \%$ & $7.1 \%$ & $13.5 \%$ & $25.5 x$ & $1.2 \%$ & $4.2 \%$ & $0,8 \%$ & 100, 0\% \\
\hline
\end{tabular}

Fonte: IBGE. Censo Demográfico, 2000. Elaboração do Departamento de Arquitetura e Urbanismo (DAU) da UFPA (2006).

S: Superior; SP: Superior Profissional; M: Médio; MI: Médio inferior; PO: Popular operário; P: Popular; PP: Popular Periférico; TG: Total geral. 
Tabela 15: Composição dos tipos (\%) (1991).

\begin{tabular}{|c|c|c|c|c|c|c|c|c|}
\hline \multirow{2}{*}{$\begin{array}{c}\text { CATEGORIAS } \\
\text { SOCIOOCUPACIOHAIS }\end{array}$} & \multicolumn{8}{|c|}{ TIPOS } \\
\hline & $\mathbf{s}$ & SP & $\mathbf{M}$ & MI & PO & $\mathbf{P}$ & PP & TG \\
\hline Ocupaçōes agrícolas & $1.2 \%$ & $1.5 x$ & $4.3 x$ & $3.4 \%$ & $13.9 \%$ & $1.7 x$ & $0.8 \%$ & $2,4 \%$ \\
\hline Grandes empresírios & $0,5 \%$ & $2,4 \%$ & $0.2 \%$ & $0.1 \%$ & $0.1 \%$ & $4.8 \%$ & $5,0 \%$ & $0.7 \%$ \\
\hline Dirigentes do setor público & $0.1 \%$ & $0.7 \%$ & $0.1 \%$ & $0,0 \%$ & $0.1 \%$ & $1,1 \%$ & $2,0 \%$ & $0.2 \%$ \\
\hline Dirigentes do setor privado & $0,0 \%$ & $0,5 \%$ & $0,0 \%$ & $0,0 \%$ & $0,0 \%$ & $1,0 \%$ & $0.7 \%$ & $0,1 \%$ \\
\hline Profissionais liberais & $0.1 \%$ & $0.5 \%$ & $0,0 \%$ & $0,0 \%$ & $0,0 \%$ & $1,1 \%$ & $3,4 \%$ & $0.1 \%$ \\
\hline Elite dirigente & $0.7 x$ & $4,0 \%$ & $0.3 x$ & $0.2 \%$ & $0.2 \%$ & $7.9 \%$ & $12.1 \%$ & $1.2 \%$ \\
\hline Profissionais autônomos & $0,5 \%$ & $1,7 \%$ & $0,3 \%$ & $0.2 \%$ & $0,0 \%$ & $1,5 \%$ & $2,7 \%$ & $0,5 \%$ \\
\hline Empregados de nivel auperior & $4,7 \%$ & $13.7 \%$ & $2,0 \%$ & $1,9 \%$ & $0.7 \%$ & $19,7 \%$ & $285 \%$ & $5,0 \%$ \\
\hline Elite intelectual & $5.2 \%$ & $15.4 \%$ & $2.3 \%$ & $2.1 \%$ & $0.7 x$ & $21.3 \%$ & $31.2 \%$ & $5.5 \%$ \\
\hline \multicolumn{9}{|l|}{ Pequenos empregadores } \\
\hline urbanos & $2,5 \%$ & $4,2 \%$ & $1,2 \%$ & $1,9 \%$ & $1,8 \%$ & $5,3 \%$ & $5,3 \%$ & $2,5 \%$ \\
\hline Comerciantes por conta própria & $5,9 \%$ & $4,8 \%$ & $5,1 \%$ & $5,6 \%$ & $5,7 \%$ & $3,8 \%$ & $2,3 \%$ & $5,5 \%$ \\
\hline Pequena burguesia & $8.4 \%$ & $9.0 \%$ & $6,3 \%$ & $7.5 \%$ & $8.5 \%$ & $9.2 \%$ & $8,6 \%$ & $8,0 \%$ \\
\hline Empregados escritórios & $10,5 \%$ & $12,1 \%$ & $4,7 \%$ & $5,8 \%$ & $1,8 \%$ & $10,5 \%$ & $5.6 \%$ & $8.7 \%$ \\
\hline Empregados supervis̄o & $5,5 \%$ & $10,0 \%$ & $2,9 \%$ & $3,1 \%$ & $1,1 \%$ & $8,4 \%$ & $5,5 \%$ & $5,0 \%$ \\
\hline Empregados técnicos & $2,6 \%$ & $4,0 \%$ & $1,6 \%$ & $1,4 \%$ & $0,3 \%$ & $3,8 \%$ & $2,5 \%$ & $2,3 \%$ \\
\hline Empregados aúde e educaçäo & $5,3 \%$ & $6,8 \%$ & $3,2 \%$ & $3,8 \%$ & $48 \%$ & $5,7 \%$ & $3,1 \%$ & $4.7 \%$ \\
\hline \multicolumn{9}{|l|}{ Empregados æegurança pública, } \\
\hline juatiça & $3,2 \%$ & $2,1 \%$ & $2,0 \%$ & $2,4 \%$ & $1,3 \%$ & $1,1 \%$ & $0,9 \%$ & $2,6 \%$ \\
\hline Setores médios & $26.9 \%$ & $35.0 \%$ & $14.5 \%$ & $17.6 \%$ & $9.5 \%$ & $30.5 \%$ & $19.6 \%$ & $23.3 \%$ \\
\hline Operários da indúatria moderna & $2,0 \%$ & $1,0 \%$ & $2,3 \%$ & $2,5 \%$ & $1,0 \%$ & $0.2 \%$ & $0.2 \%$ & $2,0 \%$ \\
\hline \multicolumn{9}{|l|}{ Operários da indúatria } \\
\hline tradicional & $4,0 \%$ & $1.2 \%$ & $5,7 \%$ & $5,9 \%$ & $4,3 \%$ & $0.5 \%$ & $0,3 \%$ & $4,7 \%$ \\
\hline \multicolumn{9}{|l|}{ Operários zerviços auxiliares da } \\
\hline induatria & $6,5 \%$ & $2,7 \%$ & $5,4 \%$ & $5,9 \%$ & $4,7 \%$ & $1,7 \%$ & $0,5 \%$ & $5,7 \%$ \\
\hline Operários da conatruçāo civil & $5,6 \%$ & $1,9 \%$ & $15,1 \%$ & $10,1 \%$ & $25,7 \%$ & $0.5 \%$ & $0.3 \%$ & $7,8 \%$ \\
\hline Artecios & $2,1 \%$ & $1,8 \%$ & $1,8 \%$ & $2,3 \%$ & $1,0 \%$ & $1,3 \%$ & $0,4 \%$ & $2,0 \%$ \\
\hline \multicolumn{9}{|l|}{ Operariado do setor } \\
\hline secundário & $20,0 x$ & $8.7 \%$ & $32.3 x$ & $27.6 \%$ & $37.7 \%$ & $4.2 x$ & $1.5 \%$ & $22.2 \%$ \\
\hline Operários do comércio & $7,1 \%$ & $5,8 \%$ & $5,1 \%$ & $5,1 \%$ & $1,4 \%$ & $4,5 \%$ & $5,8 \%$ & $5,3 \%$ \\
\hline \multicolumn{9}{|l|}{ Operários de serviços } \\
\hline especializados & $9,3 \%$ & $4,5 \%$ & $83 \%$ & $9,4 \%$ & $4,4 \%$ & $2,0 \%$ & $1,9 \%$ & $8,4 \%$ \\
\hline \multicolumn{9}{|l|}{ Operários de æarviços nāo } \\
\hline especializados & $5,5 \%$ & $2,7 \%$ & $81 \%$ & $8.2 \%$ & $7,2 \%$ & $1.5 \%$ & $0,5 \%$ & $5,6 \%$ \\
\hline \multicolumn{9}{|l|}{ Operariado do setor } \\
\hline terciário & $22.9 \%$ & $13.1 \%$ & $21.5 \%$ & $23.7 x$ & $12.9 \%$ & $8,0 \%$ & $8.1 \%$ & $21.4 \%$ \\
\hline Empregados doméaticos & $8,4 \%$ & $11,1 \%$ & $10.7 \%$ & $8,9 \%$ & $11,6 \%$ & $15,8 \%$ & $18,1 \%$ & $9,5 \%$ \\
\hline Biscateims & $5,9 \%$ & $1,9 \%$ & $7,1 \%$ & $8,4 \%$ & $4,5 \%$ & $1,4 \%$ & $0,0 \%$ & $5,2 \%$ \\
\hline Ambulantes & $0,5 \%$ & $0.2 \%$ & $0,6 \%$ & $0.7 \%$ & $0,8 \%$ & $0,0 \%$ & $0,0 \%$ & $0,5 \%$ \\
\hline \multicolumn{9}{|l|}{ Trabalhadores da } \\
\hline sobrerirência & $14.8 \%$ & $13.2 \%$ & $18,5 \%$ & $17.9 \%$ & $16.8 \%$ & $17.2 \%$ & $18,1 \%$ & 16. 1\% \\
\hline TOTAL & $100,0 \%$ & $100,0 \%$ & $100,0 x$ & $100,0 x$ & 100, 0\% & $100,0 x$ & $100,0 \%$ & $100,0 \%$ \\
\hline
\end{tabular}

Fonte: IBGE. Censo Demográfico, 2000. Elaboração do Departamento de Arquitetura e Urbanismo (DAU) da UFPA (2006).

S: Superior; SP: Superior Profissional; M: Médio; MI: Médio inferior; PO: Popular operário; P: Popular; PP: Popular Periférico; TG: Total geral.

180 
Tabela 16: Composição dos tipos (densidade) (2000).

\begin{tabular}{|c|c|c|c|c|c|c|c|c|c|}
\hline \multirow{2}{*}{$\begin{array}{c}\text { CATEGORIAS } \\
\text { SOCIOCUPACIONAIS }\end{array}$} & \multicolumn{9}{|c|}{ TIPOS } \\
\hline & $\mathbf{s}$ & MS & M & MI & $\mathbf{0}$ & PO & $\mathbf{P}$ & PP & TG \\
\hline Grandes empregadores & 5,43 & 1,34 & 0,65 & 0,44 & 0,39 & 0,20 & 0,07 & 0,21 & 1,00 \\
\hline Dirigentes do ator público & 3,80 & 1,67 & 0,76 & 0,69 & 0,42 & 0,36 & 0,29 & 0,58 & 1,00 \\
\hline Dirigentes do ator privado & 3,65 & 1,46 & 1,21 & 0,29 & 0,53 & 0,43 & 0,18 & 0,16 & 1,00 \\
\hline Pequenos empregadores & 3,22 & 1,18 & 0,90 & 0,85 & 0,76 & 0,49 & 0,37 & 0,48 & 1,00 \\
\hline \multicolumn{10}{|l|}{ Ocupaçōes artíaticase } \\
\hline similares & 1,34 & 1,13 & 1,15 & 0,77 & 1,02 & 0,73 & 0,85 & 0,59 & 1,00 \\
\hline \multicolumn{10}{|l|}{ Profissionais autónomos de } \\
\hline nivel superior & 4,47 & 1,05 & 0,85 & 1,20 & 0,43 & 0,46 & 0,33 & 0,44 & 1,00 \\
\hline \multicolumn{10}{|l|}{ Profíssionais empregados de } \\
\hline nivel superior & 4,23 & 1,33 & 0,96 & 0,56 & 0,49 & 0,43 & 0,19 & 0,23 & 1,00 \\
\hline \multicolumn{10}{|l|}{ Profissionais estatutários de } \\
\hline nivel superior & 3,93 & 1,81 & 0,94 & 0,31 & 0,43 & 0,23 & 0,19 & 0,20 & 1,00 \\
\hline Professores de nivel superior & 3,09 & 1,39 & 1,29 & 0,87 & 0,60 & 0,37 & 0,26 & 0,31 & 1,00 \\
\hline Ocupaçōes de escritório & 1,61 & 1,27 & 1,35 & 0,78 & 0,91 & 0,66 & 0,60 & 0,35 & 1,00 \\
\hline Ocupaçōes de superviต̄o & 1,98 & 1,26 & 1,10 & 0,93 & 0,82 & 0,79 & 0,52 & 0,59 & 1,00 \\
\hline Ocupaçōes técnicas & 1,45 & 1,25 & 1,37 & 0,82 & 0,92 & 0,70 & 0,58 & 0,53 & 1,00 \\
\hline \multicolumn{10}{|l|}{ Ocupaçōes médias de aúde e } \\
\hline educaçāo & 0,94 & 1,08 & 1,34 & 1,17 & 1,02 & 0,77 & 0,63 & 0,92 & 1,00 \\
\hline \multicolumn{10}{|l|}{ Ocupaçōes de segurança } \\
\hline pública, juatiça e correios & 1,03 & 1,34 & 1,32 & 1,07 & 0,88 & 0,86 & 0,59 & 0,65 & 1,00 \\
\hline Trabalhadores do comércio & 0,62 & 0,98 & 1,04 & 1,05 & 1,17 & 0,86 & 1,16 & 0,74 & 1,00 \\
\hline \multicolumn{10}{|l|}{ Prestadores de arvicos } \\
\hline especializados & 0,43 & 0,90 & 1,09 & 1,09 & 1,11 & 1,10 & 1,05 & 1,10 & 1,00 \\
\hline \multicolumn{10}{|l|}{ Preatadores de zerviços nāo } \\
\hline eapecializados & 0,30 & 0,87 & 0,91 & 0,86 & 1,16 & 1,32 & 1,25 & 1,01 & 1,00 \\
\hline \multicolumn{10}{|l|}{ Trabalhadores da indúatria } \\
\hline moderna & 0,27 & 0,80 & 0,99 & 2,05 & 1,08 & 1,39 & 1,07 & 0,79 & 1,00 \\
\hline \multicolumn{10}{|l|}{ Trabalhadores da indúat ria } \\
\hline tradicional & 0,43 & 0,84 & 0,94 & 1,47 & 1,06 & 1,23 & 1,21 & 1,10 & 1,00 \\
\hline Operários dos zerviços auxiliare & 0,38 & 0,94 & 1,02 & 1,67 & 1,03 & 1,32 & 0,99 & 0,89 & 1,00 \\
\hline Operários da conatruçäo civil & 0,11 & 0,76 & 0,63 & 0,90 & 1,09 & 1,50 & 1,69 & 1,49 & 1,00 \\
\hline Trabalhadores doméaticos & 0,83 & 0,87 & 0,72 & 0,65 & 1,02 & 1,09 & 1,42 & 1,53 & 1,00 \\
\hline Biscateimos & 0,30 & 0,85 & 0,81 & 0,78 & 1,16 & 1,26 & 1,28 & 1,40 & 1,00 \\
\hline Agricultores & 0,24 & 0,32 & 0,35 & 1,81 & 0,52 & 1,58 & 0,84 & 6,16 & 1,00 \\
\hline TOTAL & 1,00 & 1,00 & 1,00 & 1,00 & 1,00 & 1,00 & 1,00 & 1,00 & 1,00 \\
\hline
\end{tabular}

Fonte: IBGE. Censo Demográfico, 2000. Elaboração do Departamento de Arquitetura e Urbanismo (DAU) da UFPA (2006).

S: Superior; MS: Médio superior; M: Médio; MI: Médio inferior; O: Operário; PO: Popular operário; P: Popular; PP: Popular Periférico; TG: Total geral. 
Tabela 17: Distribuição das categorias socioocupacionais pelos tipos (\%) (2000).

\begin{tabular}{|c|c|c|c|c|c|c|c|c|c|}
\hline \multirow{2}{*}{$\begin{array}{l}\text { CATEGORIAS } \\
\text { SOCIOCUPACIONAIS }\end{array}$} & \multicolumn{9}{|c|}{ TIPOS } \\
\hline & $\mathbf{s}$ & MS & M & MI & 0 & PO & $\mathbf{P}$ & PP & TG \\
\hline \multicolumn{10}{|l|}{ Grandes empregadores } \\
\hline Dirigentes do setor público & 3,80 & 1,67 & 0,76 & 0,69 & 0,42 & 0,36 & 0,29 & 0,58 & 1,00 \\
\hline Dirigentes do setor privado & 3,65 & 1,46 & 1,21 & 0,29 & 0,53 & 0,43 & 0,18 & 0,16 & 1,00 \\
\hline Pequenos empregadores & 3,22 & 1,18 & 0,90 & 0,85 & 0,76 & 0,49 & 0,37 & 0,48 & 1,00 \\
\hline $\begin{array}{l}\text { Ocupaçōes artíaticase } \\
\text { similares }\end{array}$ & 1,34 & 1,13 & 1,15 & 0,77 & 1,02 & 0,73 & 0,85 & 0,59 & 1,00 \\
\hline $\begin{array}{l}\text { Profissionais autónomos de } \\
\text { nivel superior }\end{array}$ & 4,47 & 1,05 & 0,85 & 1,20 & 0,43 & 0,46 & 0,33 & 0,44 & 1,00 \\
\hline $\begin{array}{l}\text { Profissionais empregados de } \\
\text { nivel superior }\end{array}$ & 4,23 & 1,33 & 0,96 & 0,56 & 0,49 & 0,43 & 0,19 & 0,23 & 1,00 \\
\hline $\begin{array}{l}\text { Profissionais estatutários de } \\
\text { nivel superior }\end{array}$ & 3,93 & 1,81 & 0,94 & 0,31 & 0,43 & 0,23 & 0,19 & 0,20 & 1,00 \\
\hline Professores de nivel superior & 3,09 & 1,39 & 1,29 & 0,87 & 0,60 & 0,37 & 0,26 & 0,31 & 1,00 \\
\hline Ocupaçōes de escritório & 1,61 & 1,27 & 1,35 & 0,78 & 0,91 & 0,66 & 0,60 & 0,35 & 1,00 \\
\hline Ocupaçōes de supervī̄o & 1,98 & 1,26 & 1,10 & 0,93 & 0,82 & 0,79 & 0,52 & 0,59 & 1,00 \\
\hline Ocupaçōes técnicas & 1,45 & 1,25 & 1,37 & 0,82 & 0,92 & 0,70 & 0,58 & 0,53 & 1,00 \\
\hline $\begin{array}{l}\text { Ocupaçōes médias de wúde e } \\
\text { educaçāo }\end{array}$ & 0,94 & 1,08 & 1,34 & 1,17 & 1,02 & 0,77 & 0,63 & 0,92 & 1,00 \\
\hline Ocupaçōes de segurança & & & & & & & & & \\
\hline pública, juatiça e correios & 1,03 & 1,34 & 1,32 & 1,07 & 0,88 & 0,86 & 0,59 & 0,65 & 1,00 \\
\hline Trabalhadores do comércio & 0,62 & 0,98 & 1,04 & 1,05 & 1,17 & 0,86 & 1,16 & 0,74 & 1,00 \\
\hline $\begin{array}{l}\text { Prestadores de servigos } \\
\text { especializados }\end{array}$ & 0,43 & 0,90 & 1,09 & 1,09 & 1,11 & 1,10 & 1,05 & 1,10 & 1,00 \\
\hline $\begin{array}{l}\text { Prestadores de serviços näo } \\
\text { especializados }\end{array}$ & 0,30 & 0,87 & 0,91 & 0,86 & 1,16 & 1,32 & 1,25 & 1,01 & 1,00 \\
\hline $\begin{array}{l}\text { Trabalhadores da indúatria } \\
\text { moderna }\end{array}$ & 0,27 & 0,80 & 0,99 & 2,05 & 1,08 & 1,39 & 1,07 & 0,79 & 1,00 \\
\hline $\begin{array}{l}\text { Trabalhadores da indúatria } \\
\text { tradicional }\end{array}$ & 0,43 & 0,84 & 0,94 & 1,47 & 1,06 & 1,23 & 1,21 & 1,10 & 1,00 \\
\hline Operários dos zerviços auxiliare & 0,38 & 0,94 & 1,02 & 1,67 & 1,03 & 1,32 & 0,99 & 0,89 & 1,00 \\
\hline Operários da construģäo civil & 0,11 & 0,76 & 0,63 & 0,90 & 1,09 & 1,50 & 1,69 & 1,49 & 1,00 \\
\hline Trabalhadores doméaticos & 0,83 & 0,87 & 0,72 & 0,65 & 1,02 & 1,09 & 1,42 & 1,53 & 1,00 \\
\hline Biscateiros & 0,30 & 0,85 & 0,81 & 0,78 & 1,16 & 1,26 & 1,28 & 1,40 & 1,00 \\
\hline Agricultores & 0,24 & 0,32 & 0,35 & 1,81 & 0,52 & 1,58 & 0,84 & 6,16 & 1,00 \\
\hline TOTAL & 1,00 & 1,00 & 1,00 & 1,00 & 1,00 & 1,00 & 1,00 & 1,00 & 1,00 \\
\hline
\end{tabular}

Fonte: IBGE. Censo Demográfico, 2000. Elaboração do Departamento de Arquitetura e Urbanismo (DAU) da UFPA (2006).

S: Superior; MS: Médio superior; M: Médio; MI: Médio inferior; O: Operário; PO: Popular operário; P: Popular; PP: Popular Periférico; TG: Total geral. 
Tabela 18: Composição dos tipos (\%) (2000).

\begin{tabular}{|c|c|c|c|c|c|c|c|c|c|}
\hline \multirow{2}{*}{$\begin{array}{l}\text { CATEGORIAS } \\
\text { SOCIOCUPACIONAIS }\end{array}$} & \multicolumn{9}{|c|}{ TIPOS } \\
\hline & $\mathbf{s}$ & MS & M & MI & $\mathbf{0}$ & PO & $\mathbf{P}$ & PP & TG \\
\hline Grandes empregadores & 2,08 & 0,51 & 0,25 & 0,17 & 0,15 & 0,08 & 0,03 & 0,08 & 0,38 \\
\hline Dirigentes do sator público & 1,37 & 0,60 & 0,28 & 0,25 & 0,15 & 0,13 & 0,10 & 0,21 & 0,36 \\
\hline Dirigentes do ator privado & 1,77 & 0,71 & 0,59 & 0,14 & 0,26 & 0,21 & 0,09 & 0,08 & 0,48 \\
\hline Pequenos empregadores & 5,28 & 1,93 & 1,48 & 1,39 & 1,25 & 0,81 & 0,61 & 0,79 & 1,64 \\
\hline \multicolumn{10}{|l|}{ Ocupaçōes artíaticase } \\
\hline similares & 1,57 & 1,32 & 1,34 & 0,90 & 1,18 & 0,85 & 0,99 & 0,69 & 1,16 \\
\hline \multicolumn{10}{|l|}{ Profissionais autónomos de } \\
\hline nivel superior & 5,48 & 1,29 & 1,04 & 1,47 & 0,53 & 0,57 & 0,41 & 0,53 & 1,23 \\
\hline \multicolumn{10}{|l|}{ Profissionais empregados de } \\
\hline nivel superior & 9,70 & 3,06 & 2,20 & 1,29 & 1,13 & 0,99 & 0,43 & 0,54 & 2,30 \\
\hline \multicolumn{10}{|l|}{ Profissionais estatutários de } \\
\hline nivel superior & 4,66 & 2,14 & 1,12 & 0,37 & 0,51 & 0,27 & 0,22 & 0,23 & 1,19 \\
\hline Professores de nivel superior & 5,51 & 2,48 & 2,31 & 1,56 & 1,07 & 0,67 & 0,46 & 0,56 & 1,78 \\
\hline Ocupaçoses de escritório & 12,73 & 9,98 & 10,67 & 6,12 & 7,21 & 5,20 & 4,70 & 2,79 & 7,89 \\
\hline Ocupaçōes de auperviต̄o & 5,63 & 3,59 & 3,14 & 2,64 & 2,33 & 2,25 & 1,48 & 1,68 & 2,85 \\
\hline Ocupaçōes técnicas & 6,66 & 5,74 & 6,30 & 3,77 & 4,22 & 3,23 & 2,69 & 2,44 & 4,61 \\
\hline \multicolumn{10}{|l|}{ Ocupaçōes médias de aúde e } \\
\hline educaçäo & 4,05 & 4,65 & 5,77 & 5,04 & 4,42 & 3,31 & 2,70 & 3,99 & 4,32 \\
\hline \multicolumn{10}{|l|}{ Ocupaçōes de zegurança } \\
\hline pública, juatiça e correios & 2,88 & 3,75 & 3,69 & 3,00 & 2,46 & 2,40 & 1,66 & 1,83 & 2,79 \\
\hline Trabalhadores do comércio & 8,14 & 12,92 & 13,62 & 13,84 & 15,35 & 11,32 & 15,28 & 9,76 & 13,13 \\
\hline \multicolumn{10}{|l|}{ Prestadores de serviços } \\
\hline especializados & 4,53 & 9,42 & 11,47 & 11,47 & 11,71 & 11,57 & 11,01 & 11,54 & 10,51 \\
\hline \multicolumn{10}{|l|}{ Preatadores de aerviços nāo } \\
\hline especializados & 1,41 & 4,12 & 4,29 & 4,09 & 5,52 & 6,28 & 5,90 & 4,81 & 4,74 \\
\hline \multicolumn{10}{|l|}{ Trabalhadores da indúatria } \\
\hline moderna & 0,86 & 2,50 & 3,11 & 6,43 & 3,39 & 4,37 & 3,36 & 2,49 & 3,14 \\
\hline \multicolumn{10}{|l|}{ Trabalhadores da indúatria } \\
\hline tradicional & 1,96 & 3,83 & 4,29 & 6,70 & 4,84 & 5,61 & 5,52 & 5,02 & 4,56 \\
\hline Operários dos serviços auxiliare & 1,77 & 4,44 & 4,82 & 7,84 & 4,86 & 6,21 & 4,65 & 4,20 & 4,71 \\
\hline Operários da conatruçäo civil & 0,88 & 6,07 & 5,08 & 7,25 & 8,76 & 12,03 & 13,56 & 11,92 & 8,03 \\
\hline Trabalhadores dométicos & 8,89 & 9,39 & 7,78 & 6,96 & 10,97 & 11,74 & 15,22 & 16,38 & 10,74 \\
\hline Biscateims & 1,82 & 5,07 & 4,87 & 4,65 & 6,97 & 7,57 & 7,70 & 8,37 & 6,00 \\
\hline Agricultores & 0,36 & 0,47 & 0,51 & 2,67 & 0,77 & 2,33 & 1,23 & 9,08 & 1,47 \\
\hline TOTAL & 100.00 & 100.00 & 100.00 & 100.00 & 100.00 & 100.00 & 100.00 & 100.00 & 100.00 \\
\hline
\end{tabular}

Fonte: IBGE. Censo Demográfico, 2000. Elaboração do Departamento de Arquitetura e Urbanismo (DAU) da UFPA (2006).

S: Superior; MS: Médio superior; M: Médio; MI: Médio inferior; O: Operário; PO: Popular operário; P: Popular; PP: Popular Periférico; TG: Total geral. 